ARTIGO ORIGINAL ORIGINAL ARTICLE

\section{Padrões de tratamento, uso de recursos e custo do câncer de pulmão de não pequenas células avançado em instituições brasileiras privadas}

\author{
Treatment patterns, resource use and cost-of-illness of advanced \\ non-small lung cancer in Brazilian private institutions
}

Clarissa S. R. Baldotto', Guilherme S. Julian², Eldsamira Mascarenhas³, Mariana T. Laloni, Carla R. A. S. de Azevedo5, Diego Kashiura², Eloisa S. Moreira², Ana Paula Oliveira6

DOI: 10.21115/JBES.v10.n2.p86-106

\begin{abstract}
Palavras-chave:
câncer de pulmão de não pequenas células, quimioterapia, coleta de dados, sistema de saúde
\end{abstract}

\section{Keywords:}

non-small cell lung cancer, chemotherapy, data collection, healthcare system

\begin{abstract}
RESUMO
Objetivo: No Brasil, dados clínicos e custos econômicos do câncer de pulmão de não pequenas células (CPNPC) são escassos. Portanto, conduzimos este estudo para coletar dados de mundo real sobre padrões de tratamento e uso de recursos para CPNPC avançado (CPNPCa) em pacientes em instituições privadas brasileiras. Métodos: Coletamos dados de prontuários de seis instituições privadas no Brasil. Os pacientes elegíveis tinham diagnóstico de CPNPC avançado ou recorrente (estágios IIIB e IV) entre janeiro de 2011 e julho de 2014, e haviam recebido pelo menos duas linhas de quimioterapia. Dados foram resumidos usando estatísticas descritivas e os custos foram estimados pela abordagem bottom-up. Resultados: Dos 430 pacientes selecionados, 152 foram elegíveis para coleta de dados. A idade mediana dos pacientes foi de 62 anos e 55,9\% eram do sexo masculino. Entre os pacientes, $57,2 \%$ e 31,6\% receberam três e quatro linhas de tratamento, respectivamente. Dezesseis e vinte regimes foram utilizados como tratamentos de primeira e segunda linha. Bevacizumabe + carboplatina + paclitaxel $(n=32 ; 21,1 \%)$ foi o mais frequente na primeira linha, enquanto docetaxel isolado $(n=36 ; 23,7 \%)$ foi o regime mais comum de segunda linha. Hospitalizações e visitas ao pronto-socorro foram registradas em 52\% e 25\% dos pacientes, respectivamente. O custo total da coorte foi de R\$47.692.195,1 (US\$ 14.803.425,4). Conclusões: Os padrões de tratamento para pacientes com CPNPCa em instituições privadas brasileiras são heterogêneos. O alto uso e custos de recursos observados entre os pacientes da CPNPCa têm um impacto econômico significativo para o sistema de saúde privado brasileiro.
\end{abstract}

\begin{abstract}
Objective: In Brazil, data on clinical and economic burden of non-small cell lung cancer (NSCLC) are scarce. Therefore, we conducted this study to gather real-world data on treatment patterns and resource use for advanced NSCLC (aNSCLC) patients in Brazilian private institutions. Methods: We collected data from medical charts from six private institutions in Brazil. Eligible patients were diagnosed with advanced or recurrent NSCLC (stages IIIB and IV) between January 2011 and July 2014, and had received at least two lines of chemotherapy. Data were summarized using descriptive statistics and costs estimated by bottom-up approach. Results: Out of 430 charts screened, 152 were eligible for data collection. Patients' median age was 62 years, 55.9\% were male. Among patients, 57.2\%
\end{abstract}

\footnotetext{
Recebido em: 07/05/2018. Aprovado para publicação em: 23/06/2018

1. Instituto COI de Educação e Pesquisa, CA, Rio de Janeiro, RJ, Brasil.

2. Evidências - Kantar Health, São Paulo, SP, Brasil.

3. Núcleo de Oncologia da Bahia, Salvador, BA, Brasil.

4. Centro Paulista de Oncologia, São Paulo, SP, Brasil.

5. MultiHemo Oncologia e Hematologia, Recife, PE, Brasil.

6. Bristol-Myers Squibb, São Paulo, SP, Brasil.

Instituição onde o trabalho foi executado: Evidências - Kantar Health, São Paulo, SP, Brasil.

Fontes externas de financiamento: Este estudo foi financiado pela Bristol-Myers Squibb.

Conflitos de interesse: Ana Paula Oliveira é funcionária da Bristol-Myers Squibb; Guilherme Silva Julian, Eloisa de Sá Moreira e

Diego Kashiura são funcionários da Kantar Health. Os demais autores declaram não ter conflitos de interesse relevantes para a submissão do manuscrito. Este estudo foi patrocinado pela Bristol-Myers Squibb.

Autor correspondente: Ana Paula Casagrande D. Oliveira - Bristol-Myers Squibb. Rua Verbo Divino, 1711, Chácara Santo Antônio, São Paulo, SP, Brasil. CEP: 04719-002. Telefone: (+55 11) 3882-2209. E-mail: AnaPaula.Oliveira@bms.com
} 
and $31.6 \%$ had received three and four treatment lines, respectively. Sixteen and twenty regimens were used as first and second-line treatments, respectively. Bevacizumab + carboplatin + paclitaxel ( $n=32 ; 21.1 \%)$ was the most frequent first-line regimens, while docetaxel $(n=36 ; 23.7 \%)$ the most common second-line regimen. Hospitalizations and ER visits were recorded from $52 \%$ and $25 \%$ of the patients, respectively. Total cohort costs were R\$47,692,195.1 (US\$14,803,425.4). Conclusions: Treatment patterns for patients with aNSCLC in Brazilian private institutions are heterogeneous. The observed high resource use and costs among aNSCLC patients have a significant economic impact to the Brazilian private healthcare system.

\section{Introdução}

O câncer de pulmão representa o mais incidente no mundo. Em 2012, aproximadamente 1.241.600 novos casos ocorreram entre homens e 583.100 entre mulheres, sendo considerado a principal causa de morte relacionada ao câncer nos mercados desenvolvidos e emergentes (Torre et al., 2015). No Brasil, foram registrados 28.220 novos casos (17.330 homens e 10.890 mulheres) de câncer de pulmão em 2016, representando 5,9\% e 3,6\% de todos os novos casos de câncer, respectivamente (Ministério da Saúde, 2016). A classificação da Organização Mundial da Saúde (OMS) para câncer de pulmão primário reconhece quatro tipos celulares histológicos principais (Brambilla et al., 2001), e o câncer de pulmão de não pequenas células (CPNPC) é o mais comum, representando 85\% de todos os casos (Brambilla et al., 2001; Sher et al., 2008; Navada et al., 2006).

Atualmente, o sistema público de saúde brasileiro cobre aproximadamente $75 \%$ da população, mas existem desigualdades entre os sistemas público e privado em relação aos cuidados primários, ambulatoriais, secundários e de emergência (Flores et al., 2015; Garcia-Subirats et al., 2014). Na oncologia, as desigualdades são notáveis, especialmente em visitas ao médico, atendimentos em pronto-socorro (PS) e hospitalizações, que são mais frequentes em pacientes atendidos no sistema privado de saúde (Flores et al., 2015; Goozner, 2012).

Estudos de padrões de tratamento e evidências do mundo real são ferramentas essenciais no desenvolvimento de modelos econômicos e no processo de tomada de decisão. De fato, os estudos de dados do mundo real são os mais utilizados pelos órgãos de Avaliação de Tecnologia em Saúde (ATS) em todo o mundo (Stephens et al., 2012). No Brasil, poucos estudos descreveram padrões de tratamento de CPNPC avançados (CPNPCa) com detalhes sobre o esquema de tratamento (Araujo et al., 2014; Martins \& Pereira, 1999; Younes et al., 1992; de Castro et al., 2017; Lopes et al., 2015; Piedade et al., 2014; Tanaka et al., 2016). Além disso, dados sobre o uso de recursos e custos relacionados ao CPNPC são escassos, dificultando o desenvolvimento de estudos farmacoeconômicos locais. Dados publicados anteriormente sugerem que o tratamento com CPNPC pode representar um alto impacto econômico (Tanaka et al., 2016), tanto no ambiente hospitalar quanto ambulatorial (Ferreira et al., 2015). Portanto, o objetivo deste estudo é avaliar os padrões atuais de tratamento, uso de recursos e custos diretos do CPNPCa em seis instituições privadas no Brasil.

\section{Métodos}

O objetivo primário foi descrever os padrões de tratamento do CPNPCa em instituições privadas no Brasil, com foco no tratamento de segunda linha.

O estudo incluiu pacientes com idade igual ou superior a 18 anos com diagnóstico documentado de CPNPCa (estágio IIIB/IV ou doença recorrente) entre $1^{\circ}$ de janeiro de 2011 e 31 de julho de 2014. Como o objetivo do estudo foi focado no tratamento de segunda linha, os pacientes deviam ter recebido pelo menos duas linhas de tratamento sistêmico para CPNPCa por pelo menos um ciclo. Foram excluídos os pacientes com dados não confiáveis ou excesso de dados incompletos; pacientes com qualquer outro tumor não adenocarcinoma ou doença maligna (com exceção do câncer de pele não melanoma) e pacientes participando de qualquer estudo clínico durante o período de coleta de dados.

A partir da data do diagnóstico do CPNPC, foi realizada uma revisão retrospectiva do prontuário médico até o dia 7 de março de 2017 que incluiu todo o período desde o diagnóstico do CPNPCa.

\section{Tamanho da amostra}

Por ser um estudo descritivo sem hipótese formal, o tamanho da amostra foi calculado com base na margem de erro [metade da largura dos intervalos de confiança de 95\% (IC)] da proporção de pacientes que receberam diferentes opções de tratamento. Estimou-se a margem de erro em diferentes tamanhos de amostra e proporção de pacientes utilizando um determinado tratamento, e a amostra de 200 pacientes apresentou uma precisão adequada (margem de erro de 6,9\%). Segundo a OMS, o objetivo de um estudo de uso de drogas deve ser estimar indicadores percentuais que resumem valores para a amostra com um IC 95\% de mais ou menos 7,5\% (OMS, 1993). Como houve dificuldade em recrutar pacientes, interrompeu-se a revisão do prontuário em 152 pacientes. Isso não comprometeu a análise, pois foi mantida a margem de erro de 6,7\%, considerando a proporção de docetaxel utilizada na segunda linha (23,7\%). Assim, o tamanho da amostra do estudo é clinicamente significativo considerando o objetivo primário. 


\section{Uso de recursos e custos}

Os custos foram estimados com base nos dados coletados para avaliar o uso de recursos relacionados ao CPNPCa no Sistema de Saúde Privado do Brasil. Desse modo, todos os custos foram estimados sob a perspectiva do Sistema de Saúde Privado.

A estimativa dos custos médicos diretos foi baseada no método "bottom-up" com base em dados de prontuários individuais (Jo, 2014; Larg \& Moss, 2011). Os preços dos medicamentos foram obtidos da lista publicada pela Câmara de Regulação do Mercado de Medicamentos (CMED), atualizada em maio de 2017, e o preço fábrica (ICMS 18\%) foi utilizado (CMED, 2017). Os custos de material foram extraídos da Revista Simpro (Simpro, 2017). Os honorários médicos foram calculados com base na Classificação Brasileira Hierárquica de Procedimentos Médicos (CBHPM) (CBHPM, 2008).

Os custos de medicamentos, materiais e taxas foram incluídos nos grupos de quimioterapia e manutenção. Para radioterapia, cirurgia, exames, procedimentos de suporte, atendimento ambulatorial e atendimento de emergência, foram consideradas apenas as taxas médicas e de procedimentos para estimar os custos.

Se faltasse informação sobre a área da radioterapia, o menor custo unitário disponível para radioterapia era assumido. Os custos dos agentes de contraste utilizados para PET-Scan, tomografia e ressonância magnética também foram incluídos e seus custos foram derivados do Brasíndice (Brasíndice, 2017).

Custos de fisioterapia (CREFITO, 2017), e fonoaudiologia (Flores et al., 2015) foram extraídos de tabelas específicas. Cuidados de enfermagem, farmacêutico clínico e sessões de massoterapia foram relatados, mas desconsiderados na análise de custos, pois esses serviços não eram pagos com base em honorários e seus custos não eram padronizados.

A internação de pacientes foi classificada de acordo com a unidade: enfermaria geral, apartamento, unidade de terapia intensiva (UTI) e unidade semi-intensiva (semi-UTI). Para cada grupo, materiais, consultas médicas e taxa de internação foram estimados. Os custos de material foram extraídos da Revista Simpro (Simpro, 2017) e do Sindicato dos Hospitais (SINDHOSPE) (SINDHOSPE, 2016), e os custos de visitas do médico foram calculados de acordo com a tabela CBHPM (CBHPM, 2008). Uma vez que não havia dados publicados em taxas de hospitalização, foram coletados por telefone com duas organizações de manutenção de saúde em 2017. Em caso de dados perdidos relativos a um estabelecimento de saúde, foi assumido um atendimento hospitalar; no tempo de internação, adotou-se o valor mediano do grupo (8 dias). Todos os custos foram convertidos para 2017 US\$ (US\$ 1,00 = R\$ 3,2217; taxa de câmbio do Banco Central do Brasil de 26 de maio a 25 de agosto de 2017 (BCB, 2017).

A medicação de suporte não foi incluída nas estimativas de custo devido à falta de informações sobre dosagem e tempo de tratamento nos prontuários dos pacientes. Os custos dos eventos adversos (EA) não foram estimados devido à falta de informações sobre a fonte do evento (por exemplo, quimioterapia, radioterapia, doença etc.) e à impossibilidade de relacionar exames, procedimentos e cirurgias ao motivo pelo qual eles foram realizados. Assim, os custos associados ao EA não foram calculados.

\section{Análise estatística}

O conjunto completo de análises estatísticas foi realizado em todas as avaliações considerando todos os pacientes incluídos no estudo. Os pacientes considerados falhas de triagem foram agrupados de acordo com o motivo da exclusão.

Não houve hipótese formal no estudo. Os dados reportados como variáveis contínuas foram resumidos por média, desvio-padrão (DP), mediana, mínimo e máximo. A tabulação de contingência simples e cruzada descreveu variáveis categóricas, com frequências absolutas e percentuais com IC 95\%. A frequência das terapias medicamentosas de acordo com o nome genérico e tipo/classe (por exemplo, quimioterapia e terapia-alvo) foi resumida e por linha de terapia. Além disso, os tratamentos mais frequentemente relatados em cada linha de terapia foram resumidos.

Para descrever a sobrevida global (SG) após o diagnóstico de CPNPC em relação às variáveis de interesse, foram realizadas curvas de Kaplan-Meier para cada variável estudada, para verificar se havia evidência de diferenças entre as curvas por meio do teste de log-rank. Pacientes com perda de seguimento, dados ausentes sobre o status de vida ou pacientes ainda vivos no último contato foram censurados nas análises de sobrevida. O modelo de risco proporcional de Cox foi utilizado para identificar possíveis fatores prognósticos independentes e relacionar o tempo de sobrevida com as variáveis de interesse. Pacientes com dados incompletos não foram incluídos nas análises.

\section{Aspectos éticos}

Os dados para este estudo observacional retrospectivo foram coletados por meio de revisão de prontuários e os dados pessoais dos pacientes não foram divulgados e tratados de acordo com todas as leis e regulamentos locais aplicáveis. $\mathrm{O}$ estudo foi aprovado por todos os comitês de ética institucional de cada instituição participante antes de qualquer procedimento de estudo (CAAE 56011216.2.1001.5533; Instituto de Educação, Pesquisa e Gestão em Saúde; Parecer no 1.562.064)

\section{Resultados}

\section{Estudo da população}

Entre 430 pacientes selecionados, 152 (35,3\%) preencheram todos os critérios de seleção. As principais razões para a exclusões foram pacientes que não receberam tratamento de 
segunda linha para CPNPCa ou dados de prontuários incompletos/não confiáveis (Figura 1).

As características clínicas e demográficas iniciais dos pacientes incluídos no estudo são apresentadas na Tabela 1. A maioria dos pacientes era do sexo masculino (55,9\%), com idade média de 62,6 anos no momento do diagnóstico. Todos os pacientes eram de instituições privadas e a maioria era coberta pelo sistema privado de saúde, enquanto 14,5\% dos pacientes tinham apenas despesas custeadas pelo próprio paciente. As características clínicas são apresentadas na Tabela 2. A maioria dos pacientes (79,6\%) apresentava CPNPC não escamoso, e o estádio IV foi o estádio mais comum (87,5\%) no diagnóstico primário de CPNPC; 13 pacientes $(8,6 \%)$ recidivaram (Tabela 2). O peso médio dos pacientes entre as linhas de tratamento é apresentado na Tabela 3. Para o paciente em segunda linha, por exemplo, foi observado o peso médio de $68,8 \mathrm{~kg}$.

Para o diagnóstico, a broncoscopia $(20,4 \%)$ e a biópsia por agulha grossa (core) (19,1\%) foram as estratégias de amostragem mais comuns e a imuno-histoquímica (52\%) foi o método mais comum. Em testes de imagem no diagnóstico CPNPCa, tomografia computadorizada (TC), ressonância magnética (RM) e PET/TC foram os mais utilizados. Em relação aos biomarcadores, $76,3 \%$ dos pacientes foram testados para a mutação do EGFR, 25\% para translocação do ALKe 5,9\% para a mutação KRAS. Entre os pacientes testados para biomarcadores, 35,3\% eram positivos para EGFR, 15,8\% positivos para ALK e 33,3\% positivos para KRAS (Tabela 2). No teste EGFR, a maioria das amostras foi testada pela reação em cadeia da polimerase (PCR) $(71,6 \%)$, seguida da técnica de sequenciamento de DNA $(16,4 \%)$ e técnicas não informadas (12,1\%).

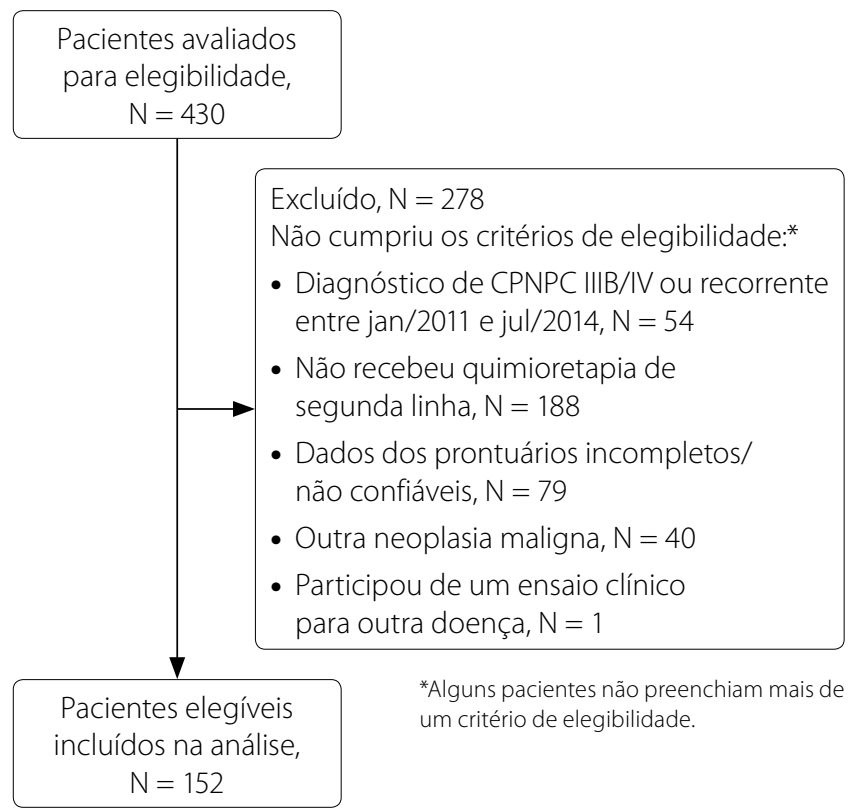

Figura 1. Fluxograma de seleção de pacientes.
Tabela 1. Dados demográficos iniciais do paciente e características clínicas no momento do diagnóstico

\begin{tabular}{|c|c|}
\hline Característica & $\begin{array}{l}\text { Número de pacientes } \\
\qquad(\mathrm{N}=152)\end{array}$ \\
\hline \multicolumn{2}{|c|}{ Idade no diagnóstico de CPNPC (anos) } \\
\hline Média (DP)* & $62,6(12,5)$ \\
\hline Mediana (intervalo) & $62(25-91)$ \\
\hline \multicolumn{2}{|l|}{ Gênero, n (\%) } \\
\hline Masculino, n (\%) & $85(55,9)$ \\
\hline \multicolumn{2}{|l|}{ Etnia, n (\%) } \\
\hline Asiática & $4(2,6)$ \\
\hline Caucasiano & $70(46,1)$ \\
\hline Negro & $6(3,9)$ \\
\hline Outros & $16(10,5)$ \\
\hline Desconhecido & $56(36,8)$ \\
\hline \multicolumn{2}{|c|}{ História familiar de câncer de pulmão, n (\%) } \\
\hline Não & $101(66,4)$ \\
\hline Sim & $23(15,1)$ \\
\hline Desconhecido & $28(18,4)$ \\
\hline \multicolumn{2}{|l|}{ Tabagismo, n (\%) } \\
\hline Não fumante & $55(36,2)$ \\
\hline Fumante & $25(16,4)$ \\
\hline Ex-fumante & $66(43,4)$ \\
\hline Desconhecido & $6(3,9)$ \\
\hline \multicolumn{2}{|l|}{ Consumo de álcool, n (\%) } \\
\hline Não consome & $61(40,1)$ \\
\hline Consome socialmente & $60(39,5)$ \\
\hline Etilista & $7(4,6)$ \\
\hline Ex-etilista & $2(1,3)$ \\
\hline Desconhecido & $22(14,5)$ \\
\hline \multicolumn{2}{|l|}{ Comorbidades, n (\%) } \\
\hline Hipertensão & $64(42,1)$ \\
\hline Diabetes (Tipo 1 ou 2) & $26(17,1)$ \\
\hline Obesidade & $10(6,6)$ \\
\hline Bronquite & $6(3,9)$ \\
\hline Enfisema & $9(5,9)$ \\
\hline Outros & $88(57,9)$ \\
\hline \multicolumn{2}{|c|}{ Cobertura dos cuidados com a saúde, n (\%) } \\
\hline Plano de saúde privado & $130(85,5)$ \\
\hline Custeado pelo paciente & $22(14,5)$ \\
\hline
\end{tabular}

* DP: desvio-padrão

\section{Terapia sistêmica}

Entre todas as coortes, a taxa de pacientes que receberam tratamento de terceira, quarta, quinta, sexta, sétima e oitava linha foi de $57,2 \%, 31,6 \%, 10,5 \%, 7,9 \%, 3,3 \%$ e $0,7 \%$, respectiva- 
Tabela 2. Doença e características do tumor

\begin{tabular}{|c|c|c|c|}
\hline Característica & $\begin{array}{l}\text { Número de pacientes } \\
\qquad(\mathrm{N}=155)\end{array}$ & Característica & $\begin{array}{l}\text { Número de pacientes } \\
\qquad(\mathrm{N}=155)\end{array}$ \\
\hline \multicolumn{2}{|l|}{ Histologia, n (\%) } & \multicolumn{2}{|c|}{ Estágio tumoral no diagnóstico primário (AJCC 7a edição), n (\%) (cont.) } \\
\hline Carcinoma de células escamosas & $26(17,1)$ & Estágio IIIA & $2(1,3)$ \\
\hline Carcinoma de células não escamosas & $121(79,6)$ & Estágio IIIB & $13(8,6)$ \\
\hline Desconhecido & $5(3,3)$ & Estágio IV & $133(87,5)$ \\
\hline \multicolumn{2}{|l|}{ Localização do tumor no diagnóstico, n (\%) } & Desconhecido & $1(0,7)$ \\
\hline \multirow{2}{*}{$\begin{array}{l}\text { Lobo superior, brônquio } \\
\text { ou pulmão (C34.1) }\end{array}$} & \multirow{2}{*}{$52(34,2)$} & \multicolumn{2}{|l|}{ Local da metástase, $\mathrm{n}$ (\% de pacientes) } \\
\hline & & Osso & $39(39,4)$ \\
\hline \multirow{2}{*}{$\begin{array}{l}\text { Lobo médio, brônquio } \\
\text { ou pulmão (C34.2) }\end{array}$} & $12(7,9)$ & Pulmões & $28(28,3)$ \\
\hline & \multirow[b]{2}{*}{$30(19,7)$} & Pleura & $24(24,2)$ \\
\hline $\begin{array}{l}\text { Lobo inferior, brônquio } \\
\text { ou pulmão (C34.3) }\end{array}$ & & Sistema nervoso central & $14(14,1)$ \\
\hline \multirow{2}{*}{$\begin{array}{l}\text { Locais sobrepostos de brônquio } \\
\text { e pulmão (C34.8) }\end{array}$} & \multirow{2}{*}{$8(5,3)$} & Linfonodos & $13(13,1)$ \\
\hline & & Fígado & $11(11,1)$ \\
\hline Partes não especificadas (C34) & $50(32,9)$ & Glândulas adrenais & $11(11,1)$ \\
\hline \multicolumn{2}{|l|}{ Método de amostragem, n (\%) } & Outros & $11(11,1)$ \\
\hline Broncoscopia & $31(20,4)$ & \multirow{2}{*}{\multicolumn{2}{|c|}{$\begin{array}{l}\text { ECOG performance status no início da } \\
\text { primeira linha de tratamento, } n(\%)\end{array}$}} \\
\hline Biópsia de agulha & $29(19,1)$ & & \\
\hline Punção aspirativa por agulha fina (PAAF) & $28(18,4)$ & \multirow{2}{*}{1} & $30(19,7)$ \\
\hline Cirurgia torácica por vídeo & $13(8,6)$ & & $84(55,3)$ \\
\hline Pleuroscopia & $13(8,6)$ & \multirow[b]{2}{*}{ Desconhecido } & $4(2,6)$ \\
\hline Biópsia de linfonodos & $6(3,9)$ & & $34(22,4)$ \\
\hline Mediastinoscopia & $6(3,9)$ & \multicolumn{2}{|l|}{ Recorrência, n (\%) } \\
\hline Toracocentese & $3(2,0)$ & Não & $139(91,4)$ \\
\hline Desconhecido & $28(18,4)$ & Sim & $13(8,6)$ \\
\hline \multicolumn{2}{|l|}{ Método de diagnóstico, n (\%) } & \multicolumn{2}{|l|}{ Terapias anteriores à recorrência*, n (\%) } \\
\hline Microscopia (Hematoxylin-Eosin) & $44(28,9)$ & Cirurgia & $8(61,5)$ \\
\hline Imuno-histoquímica (IHQ) & $79(52)$ & Radioterapia & $3(23,1)$ \\
\hline Desconhecido & $29(19,1)$ & Quimioterapia & $6(46,2)$ \\
\hline Exames de imagem no diagnóstico CPNPCa, & & Quimiorradioterapia & $3(23,1)$ \\
\hline $\mathrm{n}$ de exames (\% total de exames) & & Derrame pleural no diagnóstico CPNPCa, $\mathrm{n}$ ( & \\
\hline Tomografia & $172(34,1)$ & Sim & $55(36,2)$ \\
\hline RM & $81(16,1)$ & Não & $97(63,8)$ \\
\hline PET-CT & $80(15,9)$ & Pacientes testados para biomarcadores, n (\% & \\
\hline Radiografia & $26(5,2)$ & $\mathrm{EGFR}^{* *}$ & $116(76,3)$ \\
\hline Broncoscopia & $20(4,0)$ & $\mathrm{ALK}^{* *}$ & $38(25)$ \\
\hline Outros & $125(24,8)$ & $\mathrm{KRAS}^{* * *}$ & $9(5,9)$ \\
\hline Estágio tumoral no diagnóstico primário (AJ & C 7a edição), n (\%) & $\begin{array}{l}\text { EGFR-positivo, n (\% de } \\
\text { pacientes positivos) }\end{array}$ & $41(35,3)$ \\
\hline Estágio IA & $1(0,7)$ & ALK-positivo, n (\% de pacientes positivos) & $6(15,8)$ \\
\hline Estágio IIA & $1(0,7)$ & KRAS-positivo, n (\% de & 3 (33 3) \\
\hline Estágio IIB & $1(0,7)$ & pacientes positivos) & $2(30,3)$ \\
\hline
\end{tabular}

AJCC: American Joint Committee on Cancer; ALK: anaplastic lymphoma kinase gene; ECOG: Eastern Cooperative Study Group; EGFR: epidermal growth factor receptor gene; KRAS: Kirsten rat sarcoma viral oncogene homolog.

* Dupla contagem é possível.

** 3 pacientes necessitaram de reamostragem para testes de biomarcadores, dos quais 1 foi submetido a reamostragem por biópsia por agulha e 2, por métodos desconhecidos.

*** 1 paciente necessitou de reamostragem para o teste KRAS. O método de reamostragem utilizado era desconhecido. 
Tabela 3. Peso médio dos pacientes durante as linhas de tratamento

\begin{tabular}{|c|c|c|c|c|}
\hline \multirow[b]{2}{*}{ Peso } & \multicolumn{4}{|c|}{ Linha de tratamento } \\
\hline & $\begin{array}{l}\text { Primeira linha de } \\
\text { tratamento }(n=146)\end{array}$ & $\begin{array}{l}\text { Segunda linha de } \\
\text { tratamento }(n=142)\end{array}$ & $\begin{array}{l}\text { Terceira linha de } \\
\text { tratamento }(n=82)\end{array}$ & $\begin{array}{l}\text { Quarta linha de } \\
\text { tratamento }(n=46)\end{array}$ \\
\hline$\leq 40 \mathrm{~kg}, \mathrm{n}(\%)$ & $1(0,7)$ & $2(1,4)$ & $0(0,0)$ & $1(2,2)$ \\
\hline$>40$ kg e $\leq 50$ kg, n (\%) & $11(7,5)$ & $10(7,0)$ & $9(11,0)$ & $4(8,7)$ \\
\hline$>50$ kg e $\leq 60$ kg, n (\%) & $28(19,2)$ & $34(23,9)$ & $16(19,5)$ & $14(30,4)$ \\
\hline$>60$ kg e $\leq 70$ kg, n (\%) & $48(32,9)$ & $33(23,2)$ & $17(20,7)$ & $8(17,4)$ \\
\hline$>70$ kg e $\leq 80$ kg, n (\%) & $29(19,9)$ & $36(25,4)$ & $26(31,7)$ & $10(21,7)$ \\
\hline$>80$ kg e $\leq 90$ kg, n (\%) & $13(8,9)$ & $15(10,6)$ & $5(6,1)$ & $6(13,0)$ \\
\hline$>90$ kg e $\leq 100$ kg, n (\%) & $13(8,9)$ & $8(5,6)$ & $5(6,1)$ & $2(4,3)$ \\
\hline$>100$ kg, n (\%) & $3(2,1)$ & $4(2,8)$ & $4(4,9)$ & $1(2,2)$ \\
\hline Peso médio, kg & 69,5 & 68,8 & 69,6 & 67,7 \\
\hline
\end{tabular}

mente. Além disso, 10 pacientes (6,6\%) foram submetidos a cuidados paliativos exclusivos. A Figura 2 resume os esquemas administrados aos pacientes com CPNPCa em todas as linhas de tratamento e o número de pacientes que os receberam. Ao longo do período do estudo, 32 regimes foram relatados em adição aos regimes de ensaios clínicos.

Os regimes mais frequentemente relatados para tratamento de primeira linha foram bevacizumabe + carboplatina + paclitaxel $(21,1 \%)$, seguidos por carboplatina + pemetrexede $(20,4 \%)$ e cisplatina + pemetrexede (17,1\%) (Anexo 1). Os principais critérios para seleção do regime foram "outros" (39,5\%), seguidos da experiência clínica (17,8\%). A progressão da doença $(65,1 \%)$ e a finalização do tratamento de acordo com o protocolo inicial (21,7\%) foram os motivos mais comuns para a descontinuação do tratamento em primeira linha. Em relação às taxas de resposta na primeira linha, 38,2\% dos pacientes tiveram resposta parcial, $22,4 \%$, resposta ao tratamento desconhecida, 20,4\%, progressão da doença e 18,4\%, doença estável. Um paciente $(0,7 \%)$ apresentou resposta completa.

Na terapia de segunda linha, 20 regimes foram relatados, além dos utilizados em ensaios clínicos. O docetaxel foi a droga mais frequentemente relatada (23,7\%), seguido pelo pemetrexede $(16,4 \%)$ e pela combinação de carboplatina + pemetrexede (13,2\%) (Anexo 1). A terapia com inibidores PD-1 foi utilizada em quatro dos seis locais de pesquisa e em 20 pacientes do estudo, dos quais 19 usaram nivolumabe. Entre as razões para a seleção terapêutica, o acesso expandido ao medicamento de ensaio clínico foi o mais comum (26,3\%).

Na terapia de primeira linha, os principais critérios para seleção do regime foram classificados como "outros" (43,4\%) e baseados na experiência clínica do médico (17,8\%). Progressão da doença $(63,2 \%)$ e morte $(12,5 \%)$ foram os motivos mais comuns para a interrupção do tratamento. Na segunda linha, as taxas de resposta foram de 32,2\%, 28,3\%, 21,1\% e 17,8\% para resposta desconhecida ao tratamento, progressão da doença, resposta parcial e doença estável, respectivamente. Um paciente $(0,7 \%)$ apresentou resposta completa.
Durante o tratamento de primeira linha, os pacientes receberam uma mediana de seis ciclos (intervalo 1-31) com tempo mediano de tratamento de 3,5 meses (intervalo 0-36); $44,7 \%$ dos pacientes passaram por terapia de manutenção. No tratamento de segunda linha, os pacientes receberam uma mediana de quatro ciclos (intervalo 1-35) com tempo médio de tratamento de 3,0 meses (intervalo 1-35); apenas $11,8 \%$ dos pacientes realizaram terapia de manutenção. A terapia de manutenção teve duração mediana de 4 ciclos (intervalo 1-32) e 2,1 meses (intervalo 1-28,3) na terapia de primeira linha, e 5 ciclos (intervalo 1-21) e 3,5 meses (intervalo 1-14,4) em segunda linha.

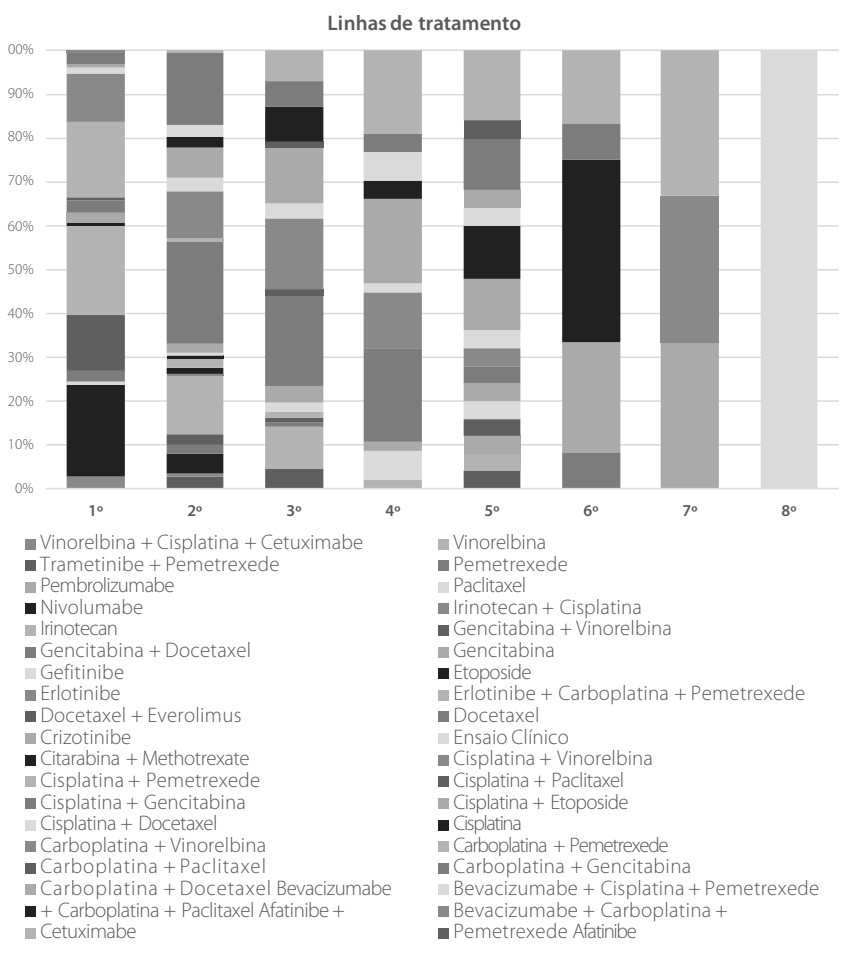

Figura 2. Regimes utilizados em todas as linhas de tratamento do estudo. 


\section{Radioterapia}

Sessenta por cento dos pacientes $(n=91)$ receberam radioterapia. O principal sítio de radiação foi osso (33,1\%; $n=52)$, seguido pelo sistema nervoso central $(31,8 \% ; n=50)$, pulmão $(21,7 \% ; n=34)$ e linfonodos $(5,7 \% ; n=9)$. A dose diária mediana foi de $3 \mathrm{~Gy}(1,8-40)$ e a mediana da dose total foi de $30 \mathrm{~Gy}$ (2-100). Os motivos de administração foram para o controle da dor $(31,2 \% ; n=49)$, quimiorradioterapia $(14,6 \% ; n=23)$, hemostática $(1,3 \% ; n=2)$ ou outra $(52,9 \% ; n=83)$. O número de pacientes submetidos à radioterapia por linha de tratamento está descrito na Tabela 4.

\section{Cirurgia}

Cirurgias foram realizadas desde a primeira até a quinta linha. Na primeira e segunda linha de tratamentos, 29 (19,1\%) e sete $(4,6 \%)$ pacientes foram submetidos a qualquer cirurgia, respectivamente (Tabela 4). Na primeira linha e na segunda linha, a metástase cerebral foi o motivo mais frequente para a cirurgia, $21,1 \%$ e $25,0 \%$, respectivamente. Nem todas as cirurgias estavam relacionadas ao tumor primário.

\section{Análise de sobrevida}

Um total de 63 pacientes foi incluído na análise de sobrevida, devido à falta de dados referentes aos demais pacientes. A mediana da SG do diagnóstico da CPNPCa foi de 26,0 meses (IC95\%: 22,7-33,2), com probabilidade de sobrevida em 3 anos de 38,1\% (IC95\%: 30,4-47,8\%). Na análise não ajustada de Kaplan-Meier, a mediana da SG de pacientes com CPNPCa não escamoso foi de 28,1 meses (24,2-38,5), enquanto a mediana da SG de pacientes com histologia escamosa foi de 19,2 meses (IC95\% 12,8-30,6). O tempo médio de seguimento desses pacientes foi de 25,6 meses (min 3,5 - máx 72,5). Na análise do modelo de Cox, com correção de análise multivariada, a histologia e o gênero foram associados à sobrevida.
De acordo com as análises, o gênero feminino apresentou maior sobrevida em relação ao gênero masculino [razão de risco: 3,25 (IC95\%: 1,51-6,98), p < 0,01]. Em relação à histologia, devido ao pequeno número de pacientes com histologia escamosa e dados disponíveis ( $\mathrm{n}<10$ ), essa variável não foi considerada para a análise de sobrevida (Figura 3).

\section{Eventos adversos}

A ocorrência de EA variou de $66,7 \%$ nos pacientes em sétima linha para $86,2 \%$ no tratamento de primeira linha. A náusea foi o EA mais frequente associado a primeira $(8,9 \%)$ e a segunda linha de tratamento (8,2\%). No geral, 3,9\% a 16,7\% dos pacientes apresentaram dados desconhecidos sobre EA (Tabela 5).

A principal causa de EA foi a quimioterapia. Oitenta e oito por cento dos casos de fadiga $(n=146), 88 \%$ de náusea

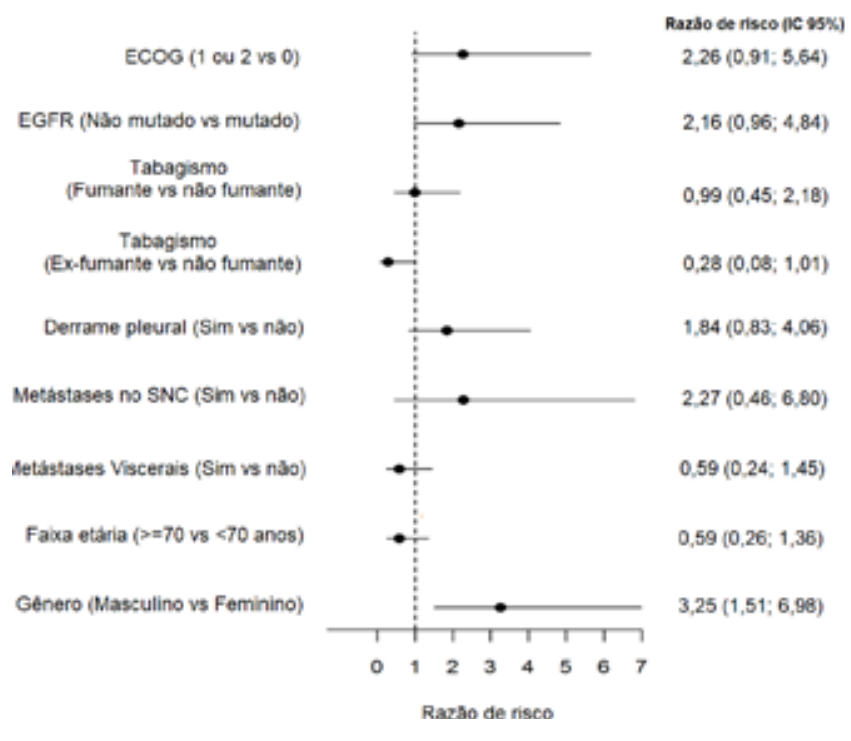

Figura 3. Análise multivariada da sobrevida global e fatores prognósticos.

Tabela 4. Frequência de uso de recursos por linha de tratamento

\begin{tabular}{|c|c|c|c|c|c|c|c|c|}
\hline \multirow[b]{2}{*}{ Recurso } & \multicolumn{8}{|c|}{ Linha de tratamento } \\
\hline & $1 \mathrm{~L}(\mathrm{n}=152)$ & $2 L(n=152)$ & $3 L(n=86)$ & $4 \mathrm{~L}(n=48)$ & $5 L(n=25)$ & $6 L(n=12)$ & $7 L(n=5)$ & $8 \mathrm{~L}(\mathrm{n}=1)$ \\
\hline Medicação concomitante & $134(88,2 \%)$ & $133(87,5 \%)$ & $75(87,2 \%)$ & $30(62,5 \%)$ & $21(84,0 \%)$ & $11(91,7 \%)$ & $4(80,0 \%)$ & $1(100 \%)$ \\
\hline Procedimentos de apoio & $36(23,7 \%)$ & $34(22,4 \%)$ & $19(22,1 \%)$ & $13(27,1 \%)$ & $7(28,0 \%)$ & $4(33,3 \%)$ & - & - \\
\hline Exames & $147(96,7 \%)$ & $145(95,4 \%)$ & $81(94,2 \%)$ & $40(83,3 \%)$ & $20(80,0 \%)$ & $11(91,7 \%)$ & $4(80,0 \%)$ & $1(100 \%)$ \\
\hline Radioterapia & $54(35,5 \%)$ & $33(21,7 \%)$ & $22(25,6 \%)$ & $4(8,3 \%)$ & $7(28,0 \%)$ & $2(16,7 \%)$ & $1(20,0 \%)$ & - \\
\hline Cirurgia & $29(19,1 \%)$ & $7(4,6 \%)$ & $7(8,1 \%)$ & $1(2,1 \%)$ & $1(4,0 \%)$ & - & - & - \\
\hline Internação & $37(24,3 \%)$ & $31(20,4 \%)$ & $21(24,4 \%)$ & $15(31,3 \%)$ & $6(24,0 \%)$ & $2(16,7 \%)$ & - & - \\
\hline Cuidado ambulatorial & $144(94,7 \%)$ & $138(90,8 \%)$ & $81(94,2 \%)$ & $42(87,5 \%)$ & $24(96,0 \%)$ & $11(91,7 \%)$ & $5(100 \%)$ & $1(100 \%)$ \\
\hline Cuidado de emergência & $12(7,9 \%)$ & $14(9,2 \%)$ & $5(5,8 \%)$ & $8(16,7 \%)$ & $1(4,0 \%)$ & $1(8,3 \%)$ & $1(20,0 \%)$ & - \\
\hline
\end{tabular}


Tabela 5. Taxa de pacientes com relato de eventos adversos e os mais comumente relatados

\begin{tabular}{|c|c|c|c|c|c|c|c|}
\hline \multirow{2}{*}{ Variável } & \multicolumn{7}{|c|}{ Linha de tratamento (número de pacientes) } \\
\hline & $1 \mathrm{~L}(n=152)$ & $2 L(n=152)$ & $3 L(n=87)$ & $4 \mathrm{~L}(n=48)$ & $5 L(n=27)$ & $6 L(n=12)$ & $7 L(n=6)$ \\
\hline & \multicolumn{7}{|c|}{ Número de pacientes (\%) } \\
\hline $\begin{array}{l}\text { Pacientes que tiveram pelo } \\
\text { menos um evento adverso }\end{array}$ & $131(86,2 \%)$ & $117(77,0 \%)$ & $74(85,1 \%)$ & $37(77,1 \%)$ & $19(70,4 \%)$ & $9(75,0 \%)$ & $4(66,7 \%)$ \\
\hline Desconhecido & $6(3,9 \%)$ & $8(5,3 \%)$ & $5(5,7 \%)$ & $5(10,4 \%)$ & $2(7,4 \%)$ & $1(8,3 \%)$ & $1(16,7 \%)$ \\
\hline Evento adverso & \multicolumn{7}{|c|}{ Número de eventos (\%)* } \\
\hline Náusea & $80(8,9 \%)$ & $61(8,2 \%)$ & $16(4,0)$ & $10(5,5 \%)$ & $2(1,5 \%)$ & $1(2,2 \%)$ & $1(6,3 \%)$ \\
\hline Fadiga & $62(6,9 \%)$ & $54(7,2 \%)$ & $22(5,5 \%)$ & $11(6,0 \%)$ & $10(7,6 \%)$ & $4(8,7 \%)$ & $2(12,5 \%)$ \\
\hline Dor & $54(6,0 \%)$ & $60(8,0 \%)$ & $30(7,4 \%)$ & $6(3,3 \%)$ & $4(3,1 \%)$ & $2(4,4 \%)$ & $1(6,3 \%)$ \\
\hline Obstipação & $51(5,7 \%)$ & $47(6,3 \%)$ & $18(4,5 \%)$ & $6(3,3 \%)$ & $3(2,3 \%)$ & $2(4,4 \%)$ & $0(0 \%)$ \\
\hline Astenia & $31(3,5 \%)$ & $32(4,3 \%)$ & $22(5,5 \%)$ & $10(5,5 \%)$ & $2(1,5 \%)$ & $4(8,7 \%)$ & $0(0 \%)$ \\
\hline Falta de apetite & $29(3,2 \%)$ & $13(1,7 \%)$ & $8(2,0 \%)$ & $6(3,3 \%)$ & $4(3,1 \%)$ & $1(2,2 \%)$ & $1(6,3 \%)$ \\
\hline Diarreia & $28(3,1 \%)$ & $26(3,5 \%)$ & $16(4,0 \%)$ & $7(3,9 \%)$ & $6(4,6 \%)$ & - & $1(6,3 \%)$ \\
\hline Falta de ar & $28(3,1 \%)$ & $20(2,7 \%)$ & $10(2,5 \%)$ & $7(3,9 \%)$ & $3(2,3 \%)$ & $3(6,5 \%)$ & $1(6,3 \%)$ \\
\hline Tosse & $25(2,8 \%)$ & $14(1,9 \%)$ & $12(3,0 \%)$ & $2(1,1 \%)$ & $4(3,1 \%)$ & $2(4,4 \%)$ & $1(6,3 \%)$ \\
\hline Mucosite & $19(2,1 \%)$ & $9(1,2 \%)$ & $8(2,0 \%)$ & $3(1,7 \%)$ & $1(0,8 \%)$ & $1(2,2 \%)$ & $1(6,3 \%)$ \\
\hline Anemia & $16(1,8 \%)$ & 17 (2,3\%) & $8(2,0 \%)$ & $5(2,8 \%)$ & $5(3,8 \%)$ & $1(2,2 \%)$ & $1(6,3 \%)$ \\
\hline Neutropenia & $18(2,0 \%)$ & $15(2,0 \%)$ & $11(2,7 \%)$ & $3(1,7 \%)$ & $2(1,5 \%)$ & - & - \\
\hline Neuropatia & $12(1,3 \%)$ & $14(1,9 \%)$ & $6(1,5 \%)$ & $6(3,3 \%)$ & - & - & - \\
\hline Edema do membro inferior & $4(0,5 \%)$ & $5(0,7 \%)$ & $1(0,3 \%)$ & $4(2,2 \%)$ & - & - & - \\
\hline Pneumonia & $8(0,9 \%)$ & $5(0,7 \%)$ & $5(1,2 \%)$ & $2(1,1 \%)$ & $5(3,8 \%)$ & - & - \\
\hline Hemoptise & $5(0,6 \%)$ & $3(0,4 \%)$ & $2(0,5 \%)$ & $2(1,1 \%)$ & $4(3,1 \%)$ & $3(6,5 \%)$ & $1(6,3 \%)$ \\
\hline Trombocitopenia & $10(1,1 \%)$ & $7(0,9 \%)$ & $1(0,3 \%)$ & - & $4(3,1 \%)$ & - & - \\
\hline Infecção & $11(1,2 \%)$ & $13(1,7 \%)$ & $7(1,7 \%)$ & $2(1,1 \%)$ & $3(2,3 \%)$ & $2(4,4 \%)$ & - \\
\hline Tontura & $10(1,1 \%)$ & $4(0,5 \%)$ & $1(0,3 \%)$ & $1(0,6 \%)$ & - & $2(4,4 \%)$ & - \\
\hline Anedonia & - & $1(0,1 \%)$ & - & - & - & $1(2,2 \%)$ & - \\
\hline Escara & - & - & - & - & - & - & $1(6,3 \%)$ \\
\hline Febre & $12(1,3 \%)$ & $7(0,9 \%)$ & $3(0,7 \%)$ & $1(0,6 \%)$ & $1(0,8 \%)$ & - & $1(6,3 \%)$ \\
\hline Perda de cabelo & - & - & - & - & - & - & $1(6,3 \%)$ \\
\hline Mucosite & $19(2,1 \%)$ & $9(1,2 \%)$ & $8(2,0 \%)$ & $3(1,7 \%)$ & $1(0,8 \%)$ & $1(2,2 \%)$ & $1(6,3 \%)$ \\
\hline
\end{tabular}

* Porcentagem relacionada ao número total de eventos ocorridos em cada linha.

( $n=149), 86 \%$ de neutropenia $(n=42), 86 \%$ de falta de apetite $(n=53)$ e $81 \%$ de casos de mucosite $(n=29)$ foram relacionados ao tratamento. A dispneia foi o EA mais comumente associado à doença (69\%), seguido por dor (52,2\%) e mialgia $(41,7 \%)$. A radioterapia foi relacionada a esofagite $(n=3 ; 6,0 \%)$, fadiga $(n=6 ; 3,6 \%)$, náusea $(n=6 ; 3,5 \%)$, vômitos $(n=1 ; 2,9 \%)$, mucosite $(n=1 ; 2,8 \%)$ e falta de apetite $(n=1 ; 1,6 \%)$. A cirurgia foi relacionada a dor $(n=2 ; 1,3 \%)$ e náusea $(n=1 ; 0,6 \%)$. Dezessete por cento das infecções $(n=6)$ não tiveram sua causa descrita como desconhecida.

Insuficiência renal, infecção e trombose foram os principais EA que causaram ou prolongaram a internação (Lopes et al., 2015). EA de insuficiência renal, dor, diarreia ou dispneia le- varam à incapacidade. Dezessete por cento dos casos de EA causaram eventos médicos de grau 3 ou 4; trombose $(21,4 \%)$, mialgia $(16,4 \%)$ e dor $(11,1 \%)$ foram as mais associadas a esse desfecho. Setenta e cinco por cento dos eventos precisaram de intervenção médica (drogas ou procedimentos).

\section{Uso de recursos e medicação concomitante}

Um total de 114 procedimentos de suporte, 1.529 exames, 65 cirurgias e 382 consultas médicas foi realizado durante o período analisado. Exames, atendimento ambulatorial e medicações concomitantes foram os recursos de saúde mais utilizados (Tabela 4). A transfusão foi o procedimento de suporte 
mais frequente, realizado em $13,8 \%$ dos pacientes, com mediana de 1 (1-3) evento por paciente; e o hemograma total foi o exame mais realizado (91,45\%; mediana de 11 [1-81] eventos por paciente) (Tabela 6). Trinta e oito pacientes receberam atendimento de emergência pelo menos uma vez, com mediana de uma visita (1-3) por paciente. Cinquenta e dois por cento dos pacientes $(n=79)$ foram hospitalizados (Tabela 6 ).

De um total de 149 eventos de internação, 74 apresentaram informações sobre os serviços mais utilizados e duração da internação. Os serviços mais comumente utilizados entre os dados relatados foi a sala reservada (51\%), seguida pela UTI (7\%), semi-UTI (5\%) e enfermaria (3\%). O tempo mediano de permanência foi de 8 dias (1-58) (Tabela 6).

$\mathrm{O}$ uso de medicações concomitantes foi alto em todas as linhas de tratamento. Na primeira linha, $88,2 \%$ dos pacientes usaram pelo menos um medicamento, $87,5 \%$ na segunda linha, $86,2 \%$ na terceira linha, $62,5 \%$ na quarta linha e $77,8 \%$ na quinta linha. As drogas concomitantes mais frequentemente utilizadas foram corticosteroides sistêmicos em primeira $(10,8 \%)$, segunda $(11,7 \%)$, terceira (10\%) e quarta linha $(12,7 \%)$. Todos os detalhes sobre medicações concomitantes usadas em cada linha de tratamento são descritos no material suplementar (Anexo 2).

\section{Custo do tratamento}

O custo total do tratamento de CPNPCa foi de R\$ 47.692.195,1. O custo total por mês foi de $\mathrm{R} \$ 13.370 .305,1$. A quimioterapia foi o principal componente e correspondeu a $67 \%$ dos custos totais, seguidos de manutenção (19\%), radioterapia (7\%), exames (5\%) e hospitalização (2\%).

O custo mediano por paciente foi estimado em R\$ 78.518,3 (ou US\$ 24.371,7) por mês. Esse custo foi maior na primeira linha ( $R \$ 32.278,7)$, na sexta linha ( $R \$ 24.662,1)$ e no tratamento de segunda linha (R\$ 18.230,7) (Tabela 7). A quimioterapia foi o componente de custo mais alto em todas as linhas de tratamento, seguida pela manutenção na primeira, segunda, quarta e quinta linha, e radioterapia na terceira e na sétima linha (Figura 4). Todos os custos detalhados por linha de tratamento estão descritos no Anexo 3.

\section{Discussão}

Este artigo descreve os padrões de tratamento baseado em dados do mundo real, o uso de recursos e o custo do CPNPCa em instituições privadas no Brasil. Vários regimes quimioterápicos diferentes foram utilizados na prática clínica, incluindo tratamentos recentemente aprovados. Este estudo corrobora com estudos anteriormente publicados com objetivos semeIhantes no Brasil e em outros países (de Castro et al., 2017; Piedade et al., 2014; Tanaka et al., 2016; Davis et al., 2015; Sacher et al., 2015; Solem et al., 2015a).
A população do estudo foi composta principalmente de homens com idade em torno de 62 anos, ex-fumantes ou fumantes atuais, com perfil semelhante ao dos Estados Unidos (Davis et al., 2015), estudos europeus e globais (Solem et al., 2015a; de Castro et al., 2017). Além disso, a amostra é semelhante às publicadas em estudos anteriores, que incluíam pacientes de instituições públicas (Martins \& Pereira, 1999; Barros et al., 2006), privadas (Araujo et al., 2014; Younes et al., 1992) e de ambos os serviços de saúde (de Castro et al., 2017). Em relação à histologia, os achados divergem da literatura publicada até 2005 no Brasil (Martins \& Pereira, 1999; Barros et al., 2006; Younes et al., 2004) e estão alinhados com os estudos publicados mais recentemente (Araujo et al., 2014; de Castro et al., 2017; Lopes et al., 2015), com a histologia não escamosa sendo a mais prevalente na literatura do país.

A maioria dos pacientes (76,3\%) foi testada para biomarcadores, percentual maior do que o observado nos Estados Unidos (Pan et al., 2013), Austrália, Alemanha e Itália, semeIhante ao observado na Espanha, Coreia e inferior ao relatado em Taiwan (de Castro et al., 2017). Essa taxa também é maior que as taxas relatadas por outros estudos brasileiros sobre CPNPC (de Castro et al., 2017; Lopes et al., 2015). Essa diferença pode ser devida ao viés de seleção das instituições incluídas no estudo, já que todos são centros de oncologia de referência do sistema saúde privado do Brasil. Além disso, todos os testes de biomarcadores com dados descritos de financiamento/reembolso (44,5\% dos pacientes testados) foram financiados pela indústria farmacêutica. Apenas em um caso foi identificado o pagamento pelo plano de saúde. As diferenças na taxa de pacientes testados podem ser mais significativas em instituições do sistema público de saúde, geralmente com financiamento escasso (Flores et al., 2015; Silva et al., 2017; Ades, 2017).

Entre os pacientes testados, 35,3\% eram positivos para EGFR, dado similar ao percentual relatado em Bacchi et al., que identificaram 30,4\% de EGFR positivo entre todas as amostras testadas (Bacchi et al., 2012). Por outro lado, a maioria dos estudos publicados sobre o status de mutação do EGFR reporta um percentual menor de pacientes positivos no Brasil, América Latina, Austrália, Estados Unidos e Europa (de Castro et al., 2017; Pan et al., 2013; de Marinis et al., 2014; Gridelli et al., 2014; Honma et al., 2014; Carneiro et al., 2014; de Melo et al., 2015; Arrieta et al., 2015), exceto Coreia do Sul e Taiwan (de Castro et al., 2017). Em relação à mutação do KRAS, a taxa de pacientes positivos é maior em comparação com a literatura (Bacchi et al., 2012; Carneiro et al., 2014; de Melo et al., 2015; Arrieta et al., 2015), provavelmente devido ao número reduzido de pacientes testados neste estudo $(n=9)$. Em relação à translocação da ALK, 15,8\% dos pacientes testados foram positivos, percentual mais alto em relação aos dados publicados na Europa e no Brasil (de Castro et al., 2017; de 
Tabela 6. Utilização de recursos durante o tratamento com CPNPCa

\begin{tabular}{|c|c|c|c|c|c|}
\hline Recurso & $\begin{array}{c}\text { Número de } \\
\text { pacientes (\%) }\end{array}$ & $\begin{array}{c}\text { Mediana } \\
\text { de eventos/ } \\
\text { paciente* } \\
\text { (mínimo/ } \\
\text { máximo) }\end{array}$ & Recurso & $\begin{array}{c}\text { Número de } \\
\text { pacientes (\%) }\end{array}$ & $\begin{array}{c}\text { Mediana } \\
\text { de eventos/ } \\
\text { paciente* } \\
\text { (mínimo/ } \\
\text { máximo) }\end{array}$ \\
\hline \multicolumn{3}{|l|}{ Procedimentos de suporte } & \multicolumn{3}{|l|}{ Cirurgia } \\
\hline Stents & $1(0,7)$ & $1(1-1)$ & Lobectomia & $1(0,7)$ & $1(1-1)$ \\
\hline Paracentese & $1(0,7)$ & $1(1-1)$ & Toracotomia & $1(0,7)$ & $1(1-1)$ \\
\hline Suporte nutricional & $20(13,2)$ & $1(1-4)$ & Ressecção do tumor primário & $1(0,7)$ & $1(1-1)$ \\
\hline Transfusão & $21(13,8)$ & $1(1-3)$ & Metástase cerebral & $11(7,2)$ & $1(1-1)$ \\
\hline Oxigenoterapia & $11(7,2)$ & $1(1-2)$ & Metástase hepática & $1(0,7)$ & $1(1-1)$ \\
\hline Fisioterapia & $12(7,9)$ & $1(1-2)$ & Drenagem torácica & $2(1,3)$ & $1(1-1)$ \\
\hline Fonoaudiologia & $1(0,7)$ & $1(1-1)$ & Toracocentese & $3(2,0)$ & $1(1-1)$ \\
\hline Psicoterapia & $17(11,2)$ & $1(1-2)$ & Pleurodese & $1(0,7)$ & $1(1-1)$ \\
\hline Outros & $30(19,7)$ & $1(1-9)$ & \multirow{2}{*}{$\begin{array}{l}\text { Pleurodese - } \\
\text { Videotoracoscopia }\end{array}$} & \multirow[b]{2}{*}{$5(3,3)$} & \multirow{2}{*}{$1(1-1)$} \\
\hline Exames & & & & & \\
\hline $\begin{array}{l}\text { Biópsia por aspiração } \\
\text { com aqulha fina }\end{array}$ & $1(0,7)$ & $1(1-1)$ & Pleurocentese/toracocentese & $7(4,6)$ & $1(1-1)$ \\
\hline Análise de expectoração & $1(0,7)$ & $1(1-1)$ & Outros & $32(21,1)$ & $1(1-1)$ \\
\hline Broncoscopia & $2(1,3)$ & $1,5(1-2)$ & & \\
\hline Cálcio & $76(50,0)$ & $4(1-35)$ & Cirurgião torácico & $9(5,9)$ & $1(1-4)$ \\
\hline Colesterol total e frações & $40(26,3)$ & $2(1-13)$ & Outro especialista & $46(30,3)$ & $2(1-12)$ \\
\hline Creatinina & $133(87,5)$ & $7(1-42)$ & Nutricionista & $86(56,6)$ & $2(1-33)$ \\
\hline $\mathrm{DHL}$ & $70(46,1)$ & $5(1-35)$ & Oncologista clínico & $142(93,4)$ & $17(2-88)$ \\
\hline Fósforo & $22(14,5)$ & $1,5(1-28)$ & Pneumologista & $8(5,3)$ & $1(1-3)$ \\
\hline Glicemia & $82(54,0)$ & $4(1-35)$ & Radiologista & $2(1,3)$ & $1(1-1)$ \\
\hline Contagem total de sangue & $139(91,5)$ & $11(1-81)$ & Radioterapeuta & $43(28,3)$ & $2(1-13)$ \\
\hline Outros & $121(79,6)$ & $23(1-334)$ & Outros & $46(30,3)$ & $2(1-69)$ \\
\hline PET-CT & $78(51,3)$ & $2,5(1-15)$ & \multirow[b]{3}{*}{ Cuidado de emergência } & & $\begin{array}{l}\text { Número } \\
\text { mediano de }\end{array}$ \\
\hline PET-Scan & $11(7,2)$ & $1(1-6)$ & & & visitas por \\
\hline Potássio & $86(56,5)$ & $4(1-35)$ & & pacientes ${ }^{* *}$ & (mín-máx) \\
\hline Radiografia & $29(19,1)$ & $1(1-13)$ & Visitas ao atendimento & 38 & $1(1-3)$ \\
\hline Ressonância magnética & $86(56,6)$ & $3(1-26)$ & de emergência & (2) & נ) \\
\hline Sódio & $85(55,9)$ & $4(1-35)$ & & Número de & $\begin{array}{c}\text { Mediana LOS em } \\
\text { dias }\end{array}$ \\
\hline T4 e/ou TSH & $55(36,2)$ & $2(1-28)$ & Internação & internações & (mín-máx) \\
\hline TGP (ALT) e/ou TGO (AST) & $103(67,8)$ & $4(1-35)$ & Total & 74 & $8(1-58)$ \\
\hline Tomografia & $133(87,5)$ & $6(1-31)$ & Enfermaria & 2 & $11(10-12)$ \\
\hline Toracoscopia & $1(0,7)$ & $2(2-2)$ & Apartamento & 38 & $8(2-58)$ \\
\hline Ultrassom & $24(15,8)$ & $1,5(1-6)$ & UTI & 7 & $15(2-54)$ \\
\hline Ureia & $111(73,0)$ & $6(1-35)$ & Semi-UTI & 4 & $10(8-40)$ \\
\hline Urina I & $40(26,3)$ & $1,5(1-8)$ & Outros & 26 & $6,5(1-30)$ \\
\hline
\end{tabular}


Tabela 7. Custo total do paciente com CPNPC avançado por mês de tratamento

\begin{tabular}{lcccc}
\hline \multirow{2}{*}{$\begin{array}{l}\text { Linha de } \\
\text { tratamento }\end{array}$} & Mediana & Custo por paciente/Mês (R\$) & Máximo & Custo de coorte por mês (R\$) \\
\cline { 2 - 5 } 1 & $R \$ 32.278,70$ & Mínimo & $R \$ 224.385,90$ & $R \$ 6.014 .919,60$ \\
\hline 2 & $R \$ 18.230,70$ & $R \$ 324,10$ & $R \$ 106.619,90$ & $R .438 .245,60$ \\
\hline 3 & $R \$ 14.912,20$ & $R \$ 44,30$ & $R \$ 129.901,70$ & $R \$ 2.020 .352,90$ \\
\hline 4 & $R \$ 13.161,40$ & $R \$ 79,30$ & $R \$ 83.952,20$ & $R \$ 850.475,40$ \\
\hline 5 & $R \$ 16.102,40$ & $R \$ 148,20$ & $R \$ 132.510,90$ & $R \$ 645.771,90$ \\
\hline 6 & $R \$ 24.622,10$ & $R \$ 1.000,40$ & $R \$ 88.169,60$ & $R \$ 351.313,00$ \\
\hline 7 & $R \$ 7.749,00$ & $R \$ 13,90$ & $R \$ 16.156,00$ & $R \$ 45.746,20$ \\
\hline 8 & $R \$ 3.480,50$ & $R \$ 4.981,00$ & $R \$ 3.480,50$ & $R \$ 3.480,50$ \\
\hline
\end{tabular}

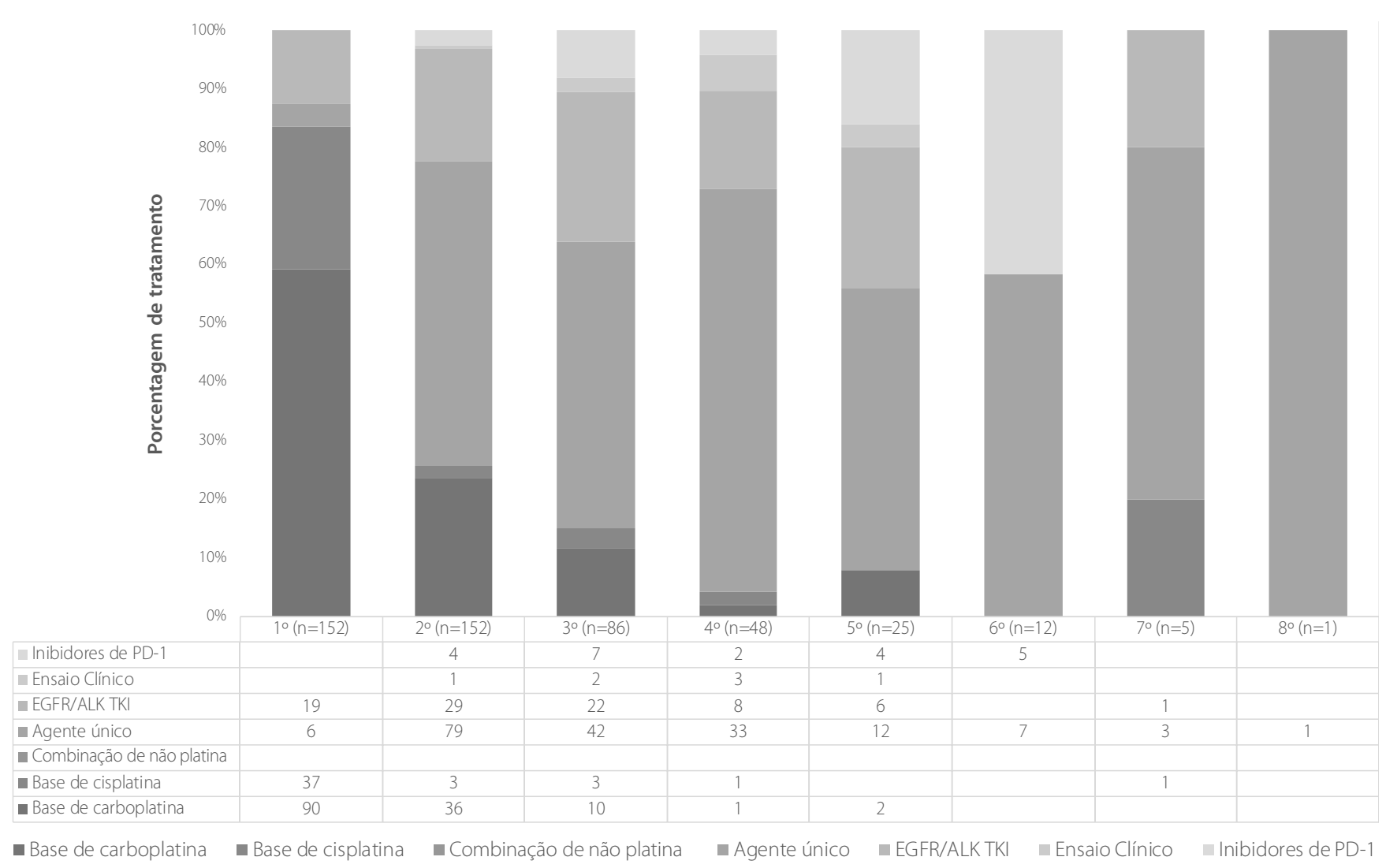

Figura 4. Percentual de gastos por categoria de custo por linha de tratamento.

Melo et al., 2015), mas menor que na Coreia do Sul e em Taiwan (de Castro et al., 2017).

Os regimes baseados em platina foram a prática clínica mais comum como terapia de primeira linha $(83,6 \%)$, conforme recomendado pelas diretrizes nacionais e internacionais (NCCN, 2017; de Sa et al., 2016) e também foram o tratamento predominante nos estudos de dados do mundo real publicados na Ásia-Pacífico, América do Norte e Europa (de Castro et al., 2017; Davis et al., 2015; Sacher et al., 2015; Solem et al., 2015a; Davies et al., 2017). No tratamento de segunda linha, a estratégia de agente único (52,0\%) foi a mais comum, seguida pelos regimes contendo platina $(23,7 \%)$ e inibidores da tirosina quinase (TKi) (19,1\%), também de acordo com as recomendações das diretrizes (NCCN, 2017; de Sa et al., 2016). As estratégias de agente único e TKi na segunda linha também corroboram dados de outros estudos de dados do mundo real na Europa (de Castro et al., 2017; de Marinis et al., 2014; Gridelli et al., 2014; Bischoff et al., 2010; Moro-Sibilot et al., 2010; 
Vergnenegre et al., 2012; Carpentier et al., 2015; Zietemann et al., 2011; Zietemann et al., 2010; Reinmuth et al., 2013; Gridelli et al., 2011), Canadá (Sacher et al., 2015), Estados Unidos (Davis et al., 2015; Pan et al., 2013), Brasil (Younes et al., 1992; de Castro et al., 2017; Lopes et al., 2015) e Ásia-Pacífico (de Castro et al., 2017). Apenas no Japão, a estratégia de segunda linha predominante no cenário do mundo real é a terapia-alvo, seguida por um agente único (Asahina et al., 2012).

Mais da metade dos pacientes da segunda linha passaram pela terceira linha de tratamento $(56,6 \%)$. Os agentes úni$\cos (48,8 \%)$ e TKi $(25,6 \%)$ foram os mais utilizados nesta linha de tratamento, à semelhança do observado na Europa (de Marinis et al., 2014; Gridelli et al., 2014; Carpentier et al., 2015; Zietemann et al., 2011; Zietemann et al., 2010; Reinmuth et al., 2013; Gridelli et al., 2011), Austrália, Taiwan, Coreia do Sul, Brasil (de Castro et al., 2017), Estados Unidos (Davis et al., 2015) e Japão (Asahina et al., 2012).

A mediana da SG deste estudo foi maior do que a dos dados publicados anteriormente na Alemanha (Reinmuth et al., 2013), Canadá (Sacher et al., 2015), Estados Unidos (Davis et al., 2015), Espanha (Corral et al., 2015) e Brasil (Araujo et al., 2014; Martins \& Pereira, 1999; Younes et al., 1992; Knust et al., 2017). Um estudo publicado recentemente com o CPNPCa na Alemanha, Itália, Espanha, Austrália, Coreia do Sul, Taiwan e Brasil - em ambientes públicos e privados - teve mediana de SG do início da primeira linha variando de 9,3 meses no Brasil a 25,5 meses em Taiwan (de Castro et al., 2017). As divergências entre os dados de SG no Brasil podem estar relacionadas ao ano de diagnóstico/tratamento do paciente (Martins \& Pereira, 1999; Younes et al., 2004), às diferenças entre a disponibilidade de tratamento (Araujo et al., 2014; Knust et al., 2017; Kaliks et al., 2017) e ao alto número de pacientes com mutação de EGFR - um fator de bom prognóstico (Zhao et al., 2017). Essas divergências também foram relatadas anteriormente em outros países (van der linden et al., 2016). Além disso, os locais de pesquisa incluídos neste estudo são considerados locais de tratamento de excelência no país.

O manejo dos EAs representou grande parte do tratamento, associado ao aumento do uso de medicações concomitantes e procedimentos de suporte (Chouaid et al., 2017). Além disso, consultas ambulatoriais, visitas ao pronto-socorro e hospitalizações também eram comuns. A radioterapia foi uma prática comum (60\%) para o manejo do CPNPCa no Brasil e muitas vezes foi administrada como tratamento de controle da dor e como parte de um regime de quimiorradioterapia. Por outro lado, um estudo de dados do mundo real de uma instituição privada brasileira descobriu que cerca de 50\% dos pacientes receberam radioterapia em algum ponto do tratamento com CPNPC (Araujo et al., 2014), enquanto na Europa estudos descrevem 12\% a 53,8\% de pacientes sob radioterapia, dependendo da linha de tratamento (Solem et al., 2015a; Migliorino et al., 2017).
O uso de recursos para o diagnóstico foi semelhante ao descrito em outros estudos, com quase todos os pacientes sendo submetidos a exames de imagem no diagnóstico, dos quais a TC, a RM e a PET foram os métodos mais utilizados; broncoscopia foi a estratégia de amostragem mais comumente utilizada (Gildea et al., 2017; Solem et al., 2015b). Neste estudo, mais de $90 \%$ dos pacientes passaram por visitas de atendimento ambulatorial durante o tratamento com CPNPCa, uma porcentagem maior em comparação com estudos do mundo real da Europa (Migliorino et al., 2017) e dos Estados Unidos (Gildea et al., 2017). Além disso, 25\% dos pacientes foram hospitalizados pelo menos uma vez durante o tratamento com CPNPC, uma taxa maior em comparação com dados da Europa, Estados Unidos e Brasil, com taxas de 0-15,7\%, 1-2\% e 13,5\%, respectivamente (Ferreira et al., 2015; Migliorino et al., 2017; Gildea et al., 2017), também com mediana do tempo de permanência dentro do intervalo daqueles relatados para os estudos na Europa (6-18 dias ou 9,3-12,8 dias), e no Brasil (9,6 dias) (Ferreira et al., 2015; Migliorino et al., 2017; Solem et al., 2015b).

Os custos referentes ao tratamento com CPNPCa foram de R\$ 78.518,3 (ou US\$ 24.371,7) por paciente/mês, com a maioria dos custos relacionados à quimioterapia, conforme publicado anteriormente em outros estudos (Honma et al., 2014; Corral et al., 2015; Knust et al., 2017; Migliorino et al., 2017; Solem et al., 2015b). O custo total do paciente por mês neste estudo foi maior do que os relatados na Europa, Estados Unidos, Holanda, Espanha e outros estudos brasileiros (Tanaka et al., 2016; Corral et al., 2015; van der linden et al., 2016; Solem et al., 2015b; McGuire et al., 2015). Algumas diferenças de custo podem ser devidas a diferenças inerentes à metodologia escolhida (Nunes et al., 2017) e a suposições e condução dos estudos (Ó Céilleachair et al., 2013). Especificamente no Brasil, os estudos são do sistema público de saúde (Knust et al., 2017) ou têm informações limitadas sobre o atendimento ao paciente, além do tratamento (Tanaka et al., 2016; Ferreira et al., 2015).

Este estudo tem algumas limitações. Uma limitação importante dos estudos retrospectivos é que os dados geralmente são incompletos e, nesse caso, podem afetar diretamente a análise de custos. Além disso, os padrões de tratamento representam apenas as práticas dos médicos que concordaram em participar do estudo e podem variar entre os médicos que não participaram. Este estudo também tem a limitação de um viés de seleção em relação aos pacientes que foram submetidos a pelo menos duas linhas de tratamento. Na análise de custos, as despesas foram padronizadas para custos do ano de 2017.

Os custos foram estimados de acordo com os preços publicados, os quais estão sujeitos a incertezas e variações. Além disso, este estudo representa apenas instituições privadas selecionadas. Custos de hospitalização divergiram en- 
tre diferentes instituições, o que pode ser devido à ausência de publicações que estimam esses valores. Por esse motivo, consideramos a abordagem de microcusteio, na qual dados incompletos em radioterapia e hospitalizações foram tratados, conforme descrito na seção de metodologia.

Os dados deste estudo indicam que existem variações no tratamento da CPNPCa no Brasil, com a utilização de novas tecnologias nos locais selecionados. Essas variações podem ter sido impactadas pelo número diferente de pacientes incluídos por local (devido à inclusão competitiva) e pelo número de diferentes regiões do país incluídas neste estudo, uma vez que a cobertura pelo sistema de saúde privado varia (ANS, 2017). A sobrevida de CPNPC foi maior que a esperada quando comparada a de outros estudos. A interpretação ou extrapolações baseadas nos resultados de SG devem ser realizadas com cuidado, devido à amostra reduzida. Muitos pacientes foram excluídos por ausência de dados, o que poderia influenciar o resultado final.

EA e uso de recursos representaram um custo significativo durante todas as linhas de tratamento, e o custo do manejo de CPNPCa foi significativamente alto. Esses resultados sugerem que a elaboração de estratégias de políticas de saúde será crucial para otimizar o tratamento de CPNPC no Brasil.

\section{Agradecimentos}

Algumas descobertas deste artigo foram apresentadas no 20 Congresso Europeu ISPOR de 2017. Este estudo foi financiado pela Bristol-Myers Squibb. Os autores agradecem o apoio de Ana Paula Caixeta, Eimy Minowa, Luiz Fernando Andrade Feijó, Renata Eiras Martins, Estela Federal e Mayara Piani e de todos os funcionários dos locais envolvidos no estudo. Os autores agradecem a Evanius Garcia Wiermann e Celio Kussomoto pela coleta de dados, a Medscale pelo apoio ao sistema eletrônico de CRF e gestão de dados e a Evidências-Kantar Health pelo levantamento dos dados, apoio estatístico e desenvolvimento de estudos.

\section{Referências bibliográficas}

Ades F. Access to oncology drugs in Brazil: juggling innovation and sustainability in developing countries. Med Access @ Point Care. 2017.1(1):e10-5.

Agência Nacional de Saúde (ANS). Dados Gerais do Setor de Planos de Saúde no Brasil. 2017 [cited 2017 07/11/2017]. Disponível em: http://www.ans. gov.br/perfil-do-setor/dados-gerais.

Araujo LH, Baldotto CS, Zukin M, Vieira FM, Victorino AP, Rocha VR, et al. Survival and prognostic factors in patients with non-small cell lung cancer treated in private health care. Rev Bras Epidemiol. 2014;17(4):1001-14.
Arrieta O, Cardona AF, Martin C, Mas-Lopez L, Corrales-Rodriguez L, Bramuglia G, et al. Updated Frequency of EGFR and KRAS Mutations in NonSmall-Cell Lung Cancer in Latin America: The Latin-American Consortium for the Investigation of Lung Cancer (CLICaP). J Thorac Oncol. 2015;10(5):838-43.

Asahina H, Sekine I, Horinouchi H, Nokihara H, Yamamoto N, Kubota K, et al. Retrospective analysis of third-line and fourth-line chemotherapy for advanced non-small-cell lung cancer. Clin Lung Cancer. 2012;13(1):39-43.

Associação Médica Brasileira. Classificação Brasileira Hierarquizada de Procedimentos Médicos. In: Brasileira AM, editor. Brasil; 2008.

Bacchi CE, Ciol H, Queiroga EM, Benine LC, Silva LH, Ojopi EB. Epidermal growth factor receptor and KRAS mutations in Brazilian lung cancer patients. Clinics (Sao Paulo). 2012;67(5):419-24.

Barros JA, Valladares G, Faria AR, Fugita EM, Ruiz AP, Vianna AG, et al. Early diagnosis of lung cancer: the great challenge. Epidemiological variables, clinical variables, staging and treatment. J Bras Pneumol. 2006;32(3):221-7.

Bischoff HG, van den Borne B, Pimentel FL, Arellano J, Langer F, Leschinger $\mathrm{MI}$, et al. Observation of the treatment and outcomes of patients receiving chemotherapy for advanced NSCLC in Europe (ACTION study). Curr Med Res Opin. 2010;26(6):1461-70.

Brambilla E, Travis WD, Colby TV, Corrin B, Shimosato Y. The new World Health Organization classification of lung tumours. Eur Respir J. 2001;18(6):1059-68.

Brasil BCd. Taxa de câmbio. 2017. Disponível em: http://www4.bcb.gov.br/ pec/taxas/port/ptaxnpesq.asp?id=txcotacao.

Brasíndice. Tabela Brasíndice. In: Brasíndice, editor. Número 870. Disponível em: http://www.brasindice.com.br/2017.

Câmara de Regulação do Mercado de Medicamentos. Lista de Preços de Medicamentos. 2017 05/2017.

Carneiro JG, Couto PG, Bastos-Rodrigues L, Bicalho MA, Vidigal PV, Vilhena A, et al. Spectrum of somatic EGFR, KRAS, BRAF, PTEN mutations and TTF-1 expression in Brazilian lung cancer patients. Genet Res (Camb). 2014;96:e002

Carpentier O, Selvaggi L, Jegu J, Purohit A, Prim N, Velten M, et al. Modern Treatments in Advanced Non-Small-Cell Lung Cancer:Temporal Trends and Effect on Survival. A French Population-Based Study. Clin Lung Cancer. 2015;16(6):496-506.

Chouaid C, Loirat D, Clay E, Millier A, Godard C, Fannan A, et al. Cost analysis of adverse events associated with non-small cell lung cancer management in France. Clinicoecon Outcomes Res. 2017;9:443-9.

Conselho Regional de Fisioterapia e Terapia Ocupacional da 10a Região. Referencial Nacional de Procedimentos Fisioterapêuticos - Valores Atualizados para 2017. In: Região CRdFeTOd, editor. 2017.

Corral J, Espinas JA, Cots F, Pareja L, Sola J, Font R, et al. Estimation of lung cancer diagnosis and treatment costs based on a patient-level analysis in Catalonia (Spain). BMC Health Serv Res. 2015 Fev 21;15:70.

Davies J, Patel M, Gridelli C, de Marinis F, Waterkamp D, McCusker ME. Realworld treatment patterns for patients receiving second-line and thirdline treatment for advanced non-small cell lung cancer: A systematic review of recently published studies. PLoS One. 2017;12(4):e0175679.

Davis KL, Goyal RK, Able SL, Brown J, Li L, Kaye JA. Real-world treatment patterns and costs in a US Medicare population with metastatic squamous non-small cell lung cancer. Lung Cancer. 2015;87(2):176-85.

de Castro J, Tagliaferri P, de Lima VCC, Ng S, Thomas M, Arunachalam A, et al. Systemic therapy treatment patterns in patients with advanced nonsmall cell lung cancer (NSCLC): PIvOTAL study. Eur J Cancer Care (Engl). 2017 Nov;26(6). 
de Marinis F, Ardizzoni A, Fontanini G, Grossi F, Cappuzzo F, Novello S, et al. Management of Italian patients with advanced non-small-cell lung cancer after second-line treatment: results of the longitudinal phase of the LIFE observational study. Clin Lung Cancer. 2014 Set;15(5):338-45 e1.

de Melo AC, Karen de Sa V, Sternberg C, Olivieri ER, Werneck da Cunha I, Fabro AT, et al. Mutational Profile and New IASLC/ATS/ERS Classification Provide Additional Prognostic Information about Lung Adenocarcinoma: A Study of 125 Patients from Brazil. Oncology. 2015;89(3):175-86

de Sa VK, Coelho JC, Capelozzi VL, de Azevedo SJ. Lung cancer in Brazil: epidemiology and treatment challenges. Lung Cancer (Auckl). 2016:7:141-8.

Ferreira CN, Santana CF, Paloni Ed, Campi Fd, Rufino CS. Lung Cancer Economic Burden From a Private Healthcare System Perspective In Brazil. Value in Health. 2015;18(3):A195.

Flores NM, Minowa E, Lee LK, Vietri J, Pomerantz D. Access Inequalities between Private and Public Insurance Among Cancer Patients: Results of a National Survey in Brazil. Value Health. 2015 Nov;18(7):A824.

Garcia-Subirats I, Vargas I, Mogollón-Pérez AS, De Paepe P, da Silva MRF, Unger JP, et al. Inequities in access to health care in different health systems: a study in municipalities of central Colombia and north-eastern Brazil. Int J Equity Health. 2014;13(1):10.

Gildea TR, DaCosta Byfield S, Hogarth DK, Wilson DS, Quinn CC. A retrospective analysis of delays in the diagnosis of lung cancer and associated costs. Clinicoecon Outcomes Res. 2017;9:261-9.

Goozner M. A tale of two countries: lung cancer care in Brazil and China. J Natl Cancer Inst. 2012 Nov 07;104(21):1621-3.

Gridelli C, Ardizzoni A, Barni S, Crino L, Caprioli A, Piazza E, et al. Medical treatment choices for patients affected by advanced NSCLC in routine clinical practice: results from the Italian observational "SUN" (Survey on the IUng cancer maNagement) study. Lung Cancer. 2011 Dez;74(3):462-8.

Gridelli C, de Marinis F, Ardizzoni A, Novello S, Fontanini G, Cappuzzo F, et al. Advanced non-small cell lung cancer management in patients progressing after first-line treatment: results of the cross-sectional phase of the Italian LIFE observational study. J Cancer Res Clin Oncol. 2014 Out;140(10):1783-93.

Honma HN, Perroud MW Jr, Leme MS, Barbeiro AS, Saad BA, Morcillo AM, et al. EGFR activating mutations and their association with response to platinum-doublet chemotherapy in Brazilian non-small cell lung cancer patients. Target Oncol. 2014 Dez;9(4):389-94.

Jo C. Cost-of-illness studies: concepts, scopes, and methods. Clin Mol Hepatol. 2014 Dez;20(4):327-37.

Kaliks R, Matos T, Silva V, Barros L. Diferenças no tratamento sistêmico do câncer no Brasil: meu SUS é diferente do teu SUS. Braz J Oncol. 2017;13(44):1-11.

Knust RE, Portela MC, Pereira CCA, Fortes GB. Estimated costs of advanced lung cancer care in a public reference hospital. Rev Saude Publica. 2017 Ago 17;51:53.

Larg A, Moss JR. Cost-of-illness studies: a guide to critical evaluation. Pharmacoeconomics. 2011;29(8):653-71.

Lopes G, Piedade A, Goes L, Alves M, Balu S. Diagnoses And Treatment Patterns For Non-Small Cell Lung Cancer (Nsclc) Within The Private Health System In Brazil. Value Health. 2015;18(7):A825.

Martins SJ, Pereira JR. Clinical factors and prognosis in non-small cell lung cancer. Am J Clin Oncol. 1999;22(5):453-7.

McGuire A, Martin M, Lenz C, Sollano JA. Treatment cost of non-small cell lung cancer in three European countries: comparisons across France, Germany, and England using administrative databases. J Med Econ. 2015;18(7):525-32.
Migliorino MR, Santo A, Romano G, Cortinovis D, Galetta D, Alabiso O, et al. Economic burden of patients affected by non-small cell lung cancer (NSCLC): the LIFE study. J Cancer Res Clin Oncol. 2017;143(5):783-91.

Ministério da Saúde, Instituto Nacional de Câncer José Alencar Gomes da Silva (INCA). Incidência de Câncer no Brasil - Estimativa 2016. In: Saúde Md, editor. Ministério da Saúde; 2016.

Moro-Sibilot D, Vergnenegre A, Smit EF, Toy E, Parente B, Schmitz S, et al. Second-line therapy for NSCLC in clinical practice: baseline results of the European SELECTTION observational study. Curr Med Res Opin. 2010;26(11):2661-72.

National Comprehensive Cancer Network. NCCN Clinical Practice Guidelines in Oncology - Non-Small Cell Lung Cancer. National Comprehensive Cancer Network; 2017.

Navada S, Lai P, Schwartz AG, Kalemkerian GP. Temporal trends in small cell lung cancer: Analysis of the national Surveillance, Epidemiology, and End-Results (SEER) database. Journal of Clinical Oncology. 2006;24(18 suppl.):7082.

Nunes SEA, Minamisava R, Vieira M, Itria A, Pessoa VPJ, Andrade A, et al. Hospitalization costs of severe bacterial pneumonia in children: comparative analysis considering different costing methods. Einstein (São Paulo). 2017;15(2):212-9.

Ó Céilleachair AJ, Hanly P, Skally M, O’Neill C, Fitzpatrick P, Kapur K, et al. Cost comparisons and methodological heterogeneity in cost-of-illness studies: the example of colorectal cancer. Med Care. 2013;51(4):339-50.

Organização Mundial da Saúde (OMS) - 1993. International Network for Rational Use of Drugs, Organization WH. How to Investigate Drug Use in Health Facilities: Selected Drug Use Indicators. Disponível em: http:// apps.who.int/medicinedocs/en/d/Js2289e/.

Pan IW, Mallick R, Dhanda R, Nadler E. Treatment patterns and outcomes in patients with non-squamous advanced non-small cell lung cancer receiving second-line treatment in a community-based oncology network. Lung Cancer. 2013;82(3):469-76.

Piedade A, Goes L, Castro AP, Alves AF, Minowa E. The Burden of Non-Small Cells Lung Cancer (NSCLC) in First Line (1L) Treatment: Patterns of Care and Cost of Illness. Value Health. 2014;17(7):A626-7.

Reinmuth N, Payer N, Muley T, Hoffmann H, Herth FJ, Villalobos M, et al. Treatment and outcome of patients with metastatic NSCLC: a retrospective institution analysis of 493 patients. Respir Res. 2013 Dez 18;14:139.

Sacher AG, Le LW, Lau A, Earle CC, Leighl NB. Real-world chemotherapy treatment patterns in metastatic non-small cell lung cancer: Are patients undertreated? Cancer. 2015 Ago 01;121(15):2562-9.

Sher T, Dy GK, Adjei AA. Small Cell Lung Cancer. Mayo Clin Proc. 2008;83(3):355-67.

Silva GAE, Souza-Junior PRB, Damacena GN, Szwarcwald CL. Early detection of breast cancer in Brazil: data from the National Health Survey, 2013. Rev Saude Publica. 2017;51(suppl 1):14s.

Simpro. Revista Simpro Hospitalar. Junho/Julho 2017, Ano 19, no 110. 2017.

Sindicato dos Hospitais CeLdEdSP. SINDHOSPE Referencial de Preços. In: Sindicato dos Hospitais CeLdEdSP, editor. 2016.

Solem C, Penrod J, Lees M, Daumont MM, Macahilig C, Baeten S, et al. 3115 Real-world treatment patterns among patients with advanced non-small cell lung cancer in Europe: Evidence from a retrospective chart review in France, Germany, Italy and Spain. Eur J Cancer. 2015a;51(suppl. 3):S641.

Solem CT, Penrod JR, Lees M, Manley Daumont M, Macahilig CP, Baeten S, et al. Resource Utilization Among Advanced Squamous and nonSquamous non-Small Cell Lung Cancer Patients Receiving SecondLine Treatment in France, Germany, Italy, and Spain: Results of A Retrospective Medical Chart Review. Value Health. 2015b;18(7):A450. 
Stephens J, Handke B, Doshi J. International survey of methods used in health technology assessment (HTA): does practice meet the principles proposed for good research? Comparative Effectiveness Research. 2012:2:29-44.

Tanaka S, Chadid T, Bernardino G. Costs and treatment patterns in patients with advanced non-small cell lung cancer in the private health system. JBES. 2016;2(8):149-54.

Torre LA, Bray F, Siegel RL, Ferlay J, Lortet-Tieulent J, Jemal A. Global Cancer Statistics, 2012. CA Cancer J Clin. 2015;65(2):87-108.

van der Linden N, Bongers ML, Coupe VM, Smit EF, Groen HJ, Welling A, et al. Costs of non-small cell lung cancer in the Netherlands. Lung Cancer. 2016;91:79-88.

Vergnenegre A, Smit EF, Toy E, Parente B, Schmitz S, Kraaij K, et al. Secondline therapy for non-small cell lung cancer in clinical practice: final results and treatment pathways from the SELECTTION observational study. Curr Med Res Opin. 2012;28(8):1253-62.
Younes RN, Deutsch F, Badra C, Gross J, Haddad F, Deheinzelin D. Nonsmall cell lung cancer: evaluation of 737 consecutive patients in a single institution. Rev Hosp Clin Fac Med São Paulo. 2004;59(3):119-27.

Younes RN, Pereira JR, Fares AL, Gross JL. Chemotherapy beyond first-line in stage IV metastatic non-small cell lung cancer. Rev Assoc Med Bras (1992). 2011;57(6):686-91.

Zhao D, Chen X, Qin N, Su D, Zhou L, Zhang Q, et al. The prognostic role of EGFR-TKIs for patients with advanced non-small cell lung cancer. Scientific Reports. 2017 01/12/online;7:40374.

Zietemann V, Duell T. Every-day clinical practice in patients with advanced non-small-cell lung cancer. Lung Cancer. 2010;68(2):273-7.

Zietemann V, Duell T. Prevalence and effectiveness of first-, second-, and third-line systemic therapy in a cohort of unselected patients with advanced non-small cell lung cancer. Lung Cancer. 2011;73(1):70-7.

Anexo 1. Descrição dos esquemas utilizados no tratamento do câncer de pulmão não pequenas células e custo total por paciente/mês, de acordo com a linha de tratamento

\begin{tabular}{|c|c|c|c|c|c|c|}
\hline \multirow[b]{2}{*}{ Regime de quimioterapia } & \multicolumn{2}{|c|}{$\begin{array}{l}\text { Primeira linha } \\
\quad(n=152)\end{array}$} & \multicolumn{2}{|c|}{$\begin{array}{l}\text { Segunda linha } \\
\qquad(n=152)\end{array}$} & \multicolumn{2}{|c|}{$\begin{array}{l}\text { Terceira linha } \\
\quad(n=86)\end{array}$} \\
\hline & $\begin{array}{l}\text { Frequência } \\
\text { n (\%) }\end{array}$ & $\begin{array}{l}\text { Mediana dos custos } \\
(\text { min-max) (R\$) }\end{array}$ & $\begin{array}{l}\text { Frequência } \\
\text { n (\%) }\end{array}$ & $\begin{array}{l}\text { Mediana dos custos } \\
\text { (min-max) }\end{array}$ & $\begin{array}{l}\text { Frequência } \\
\text { n (\%) }\end{array}$ & $\begin{array}{l}\text { Mediana dos custos } \\
\text { (min-max) }\end{array}$ \\
\hline Afatinibe & - & & $4(2,6)$ & $\begin{array}{c}5.553,49 \\
(4.026-20.307,61)\end{array}$ & $2(2,3)$ & $\begin{array}{c}5.196,38 \\
(4.823,73-5.569,03)\end{array}$ \\
\hline Afatinibe + Cetuximabe & - & & - & & 0 & \\
\hline $\begin{array}{l}\text { Bevacizumabe + Carboplatina } \\
+ \text { Pemetrexede }\end{array}$ & $4(2,6)$ & $\begin{array}{c}78.357,54 \\
(48.476,97-81.102,98)\end{array}$ & $1(0,7)$ & $32.885,91$ & 0 & \\
\hline $\begin{array}{l}\text { Bevacizumabe + } \\
\text { Carboplatina + Paclitaxel }\end{array}$ & $32(21,1)$ & $\begin{array}{c}62.288,57 \\
(11.409,44-224.385,88)\end{array}$ & $7(4,6)$ & $\begin{array}{c}43.863,6 \\
(19.132,96-74.361,47)\end{array}$ & 0 & \\
\hline $\begin{array}{l}\text { Bevacizumabe + Cisplatina } \\
+ \text { Pemetrexede }\end{array}$ & $1(0,7)$ & $172.127,64$ & - & & - & \\
\hline Carboplatina + Docetaxel & - & & - & & - & \\
\hline Carboplatina + Gencitabina & $4(2,6)$ & $\begin{array}{c}6.432,03 \\
(4.229,71-19.913,90) \\
\end{array}$ & $3(2)$ & $\begin{array}{c}5.142,9 \\
(3.714,96-60.243,73) \\
\end{array}$ & - & \\
\hline Carboplatina + Paclitaxel & $19(12,5)$ & $\begin{array}{c}15.720,28 \\
(1.035,3-88.486,49)\end{array}$ & $4(2,6)$ & $\begin{array}{c}16.664,54 \\
(11.547,81-51.972,11)\end{array}$ & $2(2,3)$ & $\begin{array}{c}9.237,86 \\
(8.362,09-10.113,63)\end{array}$ \\
\hline Carboplatina + Pemetrexede & $31(20,4)$ & $\begin{array}{c}40.401,15 \\
(9.382,94-105.156,84)\end{array}$ & $20(13,2)$ & $\begin{array}{c}38.930,59 \\
(11.993,2-99.514,97)\end{array}$ & $8(9,3)$ & $\begin{array}{c}31.786,46 \\
(79,33-47.058,93)\end{array}$ \\
\hline Carboplatina + Vinorelbina & - & & $1(0,7)$ & $5.560,56$ & - & \\
\hline Cisplatina & $1(0,7)$ & $13.349,06$ & $2(1,3)$ & $\begin{array}{c}24.841,62 \\
(15.752,81-33.930,42)\end{array}$ & - & \\
\hline Cisplatina + Etoposide & $4(2,6)$ & $\begin{array}{c}15.229,39 \\
(2.629,12-27.609,03)\end{array}$ & - & & - & \\
\hline Cisplatina + Gencitabina & $4(2,6)$ & $\begin{array}{c}17.130,82 \\
(6.560,26-195.555,9)\end{array}$ & - & & $1(1,2)$ & $6.639,55$ \\
\hline
\end{tabular}




\begin{tabular}{|c|c|c|c|c|c|c|}
\hline Cisplatina + Paclitaxel & $1(0,7)$ & $8.212,13$ & - & & $1(1,2)$ & $15.717,49$ \\
\hline Cisplatina + Pemetrexede & $26(17,1)$ & $\begin{array}{c}37.535,24 \\
(722,6-99.064,23)\end{array}$ & $3(2)$ & $\begin{array}{c}26.446,19 \\
(23.608,94-29.349,33)\end{array}$ & $1(1,2)$ & $25.651,77$ \\
\hline Citarabina + Metotrexato & - & & $1(0,7)$ & $12.018,34$ & - & \\
\hline Ensaio clínico & - & & $1(0,7)$ & $1.156,55$ & $2(2,3)$ & $\begin{array}{c}3.345,71 \\
(2.351,5-4.339,91)\end{array}$ \\
\hline Crizotinibe & - & & $3(2)$ & $\begin{array}{c}16.756,29 \\
(16.237,08-28.689)\end{array}$ & $3(3,5)$ & $\begin{array}{c}44.500,98 \\
(7.877,18-72.106,2)\end{array}$ \\
\hline Docetaxel & - & & $36(23,7)$ & $\begin{array}{c}17.244,52 \\
(337,5-62.358,09)\end{array}$ & $18(20,9)$ & $\begin{array}{c}17.504,5 \\
(2.329,97-94.662,02)\end{array}$ \\
\hline Docetaxel + Everolimo & - & & - & & $1(1,2)$ & $18.372,53$ \\
\hline $\begin{array}{l}\text { Erlotinibe + Carboplatina } \\
+ \text { Pemetrexede }\end{array}$ & - & & $1(0,7)$ & $26.236,6$ & - & \\
\hline Erlotinibe & $17(11,2)$ & $\begin{array}{c}8.081,36 \\
(324,12-14.508,17)\end{array}$ & $16(10,5)$ & $\begin{array}{c}6.981,48 \\
(44,29-27.511,39)\end{array}$ & $14(16,3)$ & $\begin{array}{c}8.511,71 \\
(2.243,56-7.7424,39) \\
\end{array}$ \\
\hline Gefitinibe & $2(1,3)$ & $\begin{array}{c}8.666,57 \\
(4.519-12.814,14) \\
\end{array}$ & $5(3,3)$ & $\begin{array}{c}4.680,61 \\
(4.261,08-6.554)\end{array}$ & $3(3,5)$ & $\begin{array}{c}4.890,52 \\
(4.858,1-5.681,16) \\
\end{array}$ \\
\hline Gencitabina & $1(0,7)$ & $6.878,96$ & $10(6,6)$ & $\begin{array}{c}7.033,9 \\
(5.634,21-52.564,04)\end{array}$ & $11(12,8)$ & $\begin{array}{c}9.293,56 \\
(6.192,4-64.895) \\
\end{array}$ \\
\hline Gencitabina + Vinorelbina & - & & - & & $1(1,2)$ & $10.107,86$ \\
\hline Irinotecan + Cisplatina & - & & - & & - & \\
\hline Nivolumabe & - & & $4(2,6)$ & $\begin{array}{c}54.750,37 \\
(43.939,38-66.234,91)\end{array}$ & $7(8,1)$ & $\begin{array}{c}5.9831,77 \\
(37.790,67-129.901,67)\end{array}$ \\
\hline Paclitaxel & - & & $4(2,6)$ & $\begin{array}{c}15.152,01 \\
(7.986,44-22.965,94)\end{array}$ & - & \\
\hline Pembrolizumabe & - & & - & & - & \\
\hline Pemetrexede & $4(2,6)$ & $\begin{array}{c}30.069,03 \\
(12.552,78-41.480,9)\end{array}$ & $25(16,4)$ & $\begin{array}{c}23.024,5 \\
(10.498,75-106.619,87)\end{array}$ & $5(5,8)$ & $\begin{array}{c}24.349,58 \\
(17.786,71-30.208,18)\end{array}$ \\
\hline Trametinibe + Pemetrexede & - & & - & & - & \\
\hline Vinorelbina & - & & $1(0,7)$ & $42.376,38$ & $6(7)$ & $\begin{array}{c}6.982,06 \\
(4.356,34-83.687,38)\end{array}$ \\
\hline $\begin{array}{l}\text { Vinorelbina + Cisplatina } \\
+ \text { Cetuximabe }\end{array}$ & $1(0,7)$ & $15.893,78$ & - & & - & \\
\hline
\end{tabular}

* Nos pacientes do Ensaio Clínico, o medicamento do tratamento foi mantido excluído e o valor do tratamento não foi considerado nos custos totais. 
Anexo 2. Medicação concomitante classificada pelo ATC de acordo com a linha de tratamento

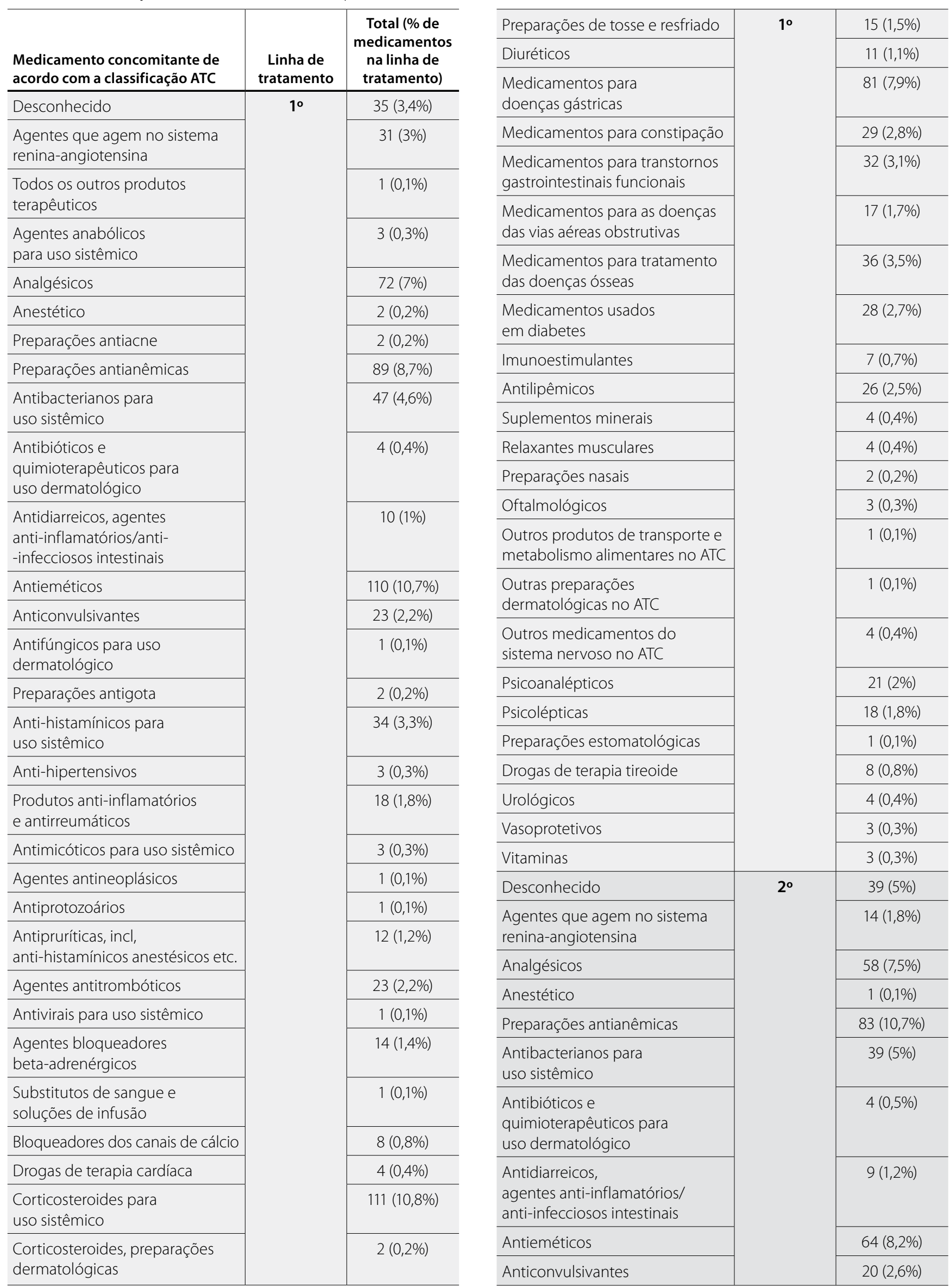




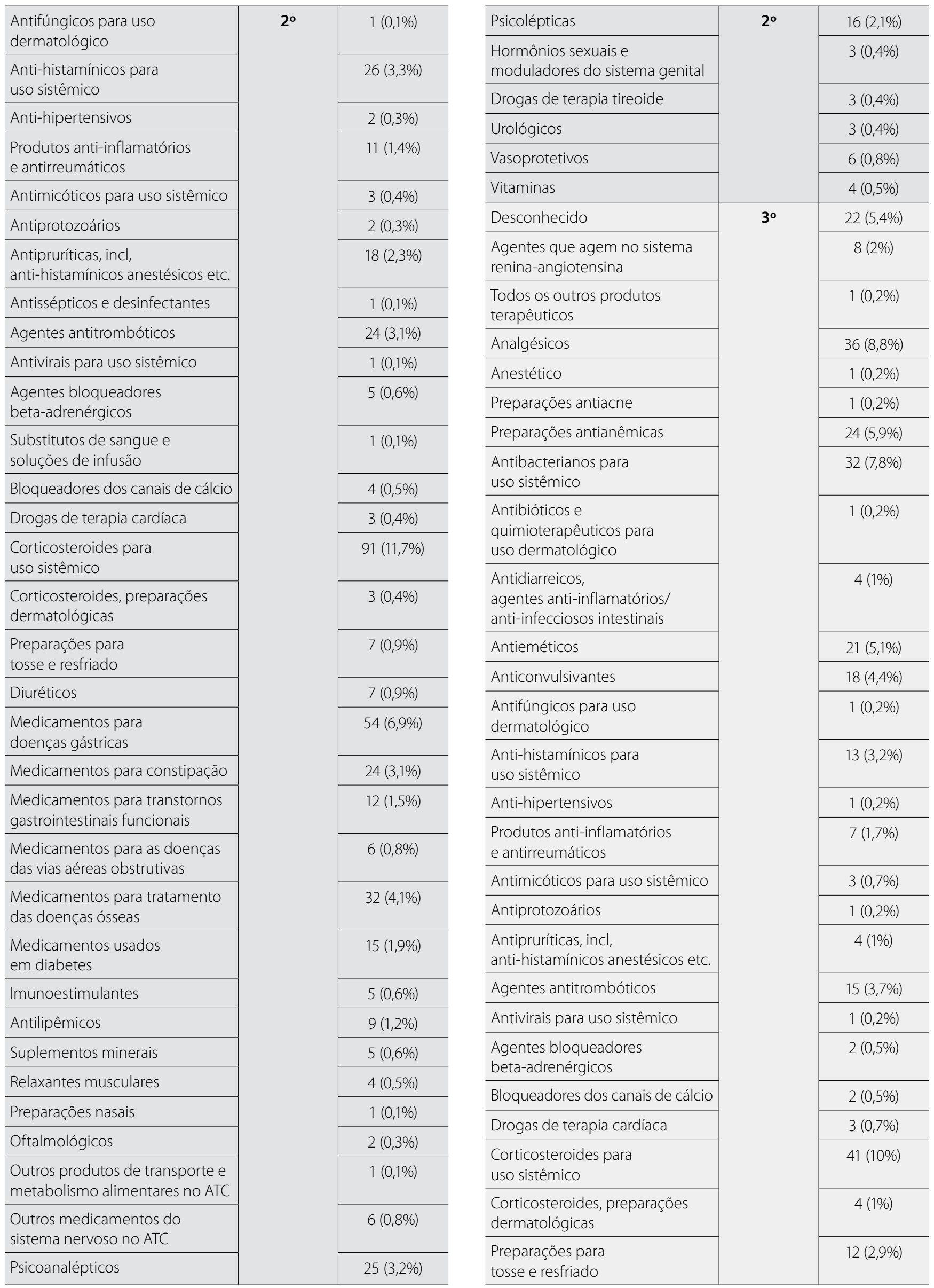




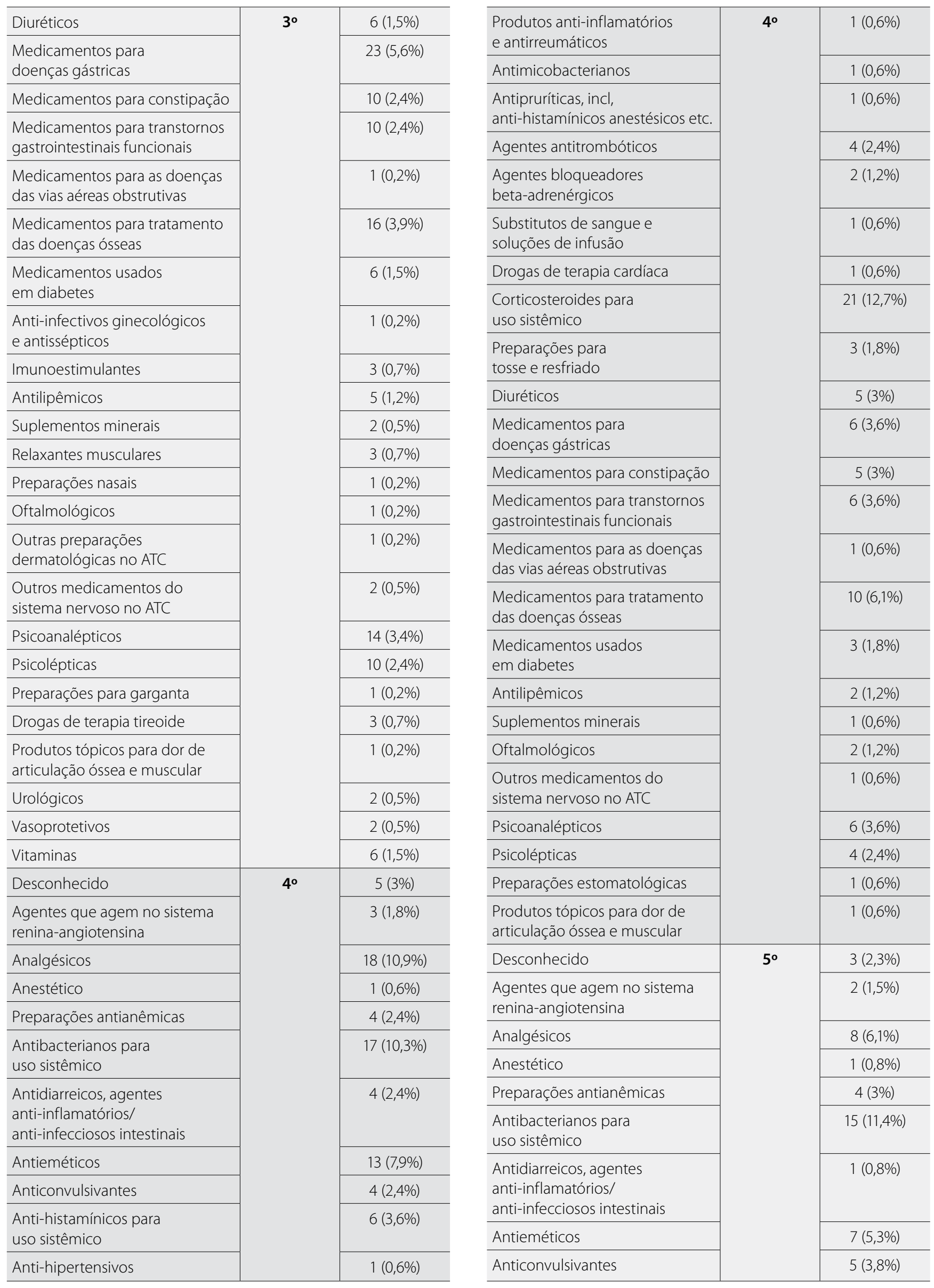




\begin{tabular}{|c|c|c|}
\hline $\begin{array}{l}\text { Anti-histamínicos para } \\
\text { uso sistêmico }\end{array}$ & \multirow[t]{27}{*}{$5^{\circ}$} & $2(1,5 \%)$ \\
\hline $\begin{array}{l}\text { Produtos anti-inflamatórios } \\
\text { e antirreumáticos }\end{array}$ & & $2(1,5 \%)$ \\
\hline Antimicóticos para uso sistêmico & & $4(3 \%)$ \\
\hline $\begin{array}{l}\text { Antipruríticas, incl, } \\
\text { anti-histamínicos anestésicos etc. }\end{array}$ & & $2(1,5 \%)$ \\
\hline Agentes antitrombóticos & & $6(4,5 \%)$ \\
\hline $\begin{array}{l}\text { Agentes bloqueadores } \\
\text { beta-adrenérgicos }\end{array}$ & & $1(0,8 \%)$ \\
\hline Drogas de terapia cardíaca & & $3(2,3 \%)$ \\
\hline $\begin{array}{l}\text { Corticosteroides para } \\
\text { uso sistêmico }\end{array}$ & & $12(9,1 \%)$ \\
\hline $\begin{array}{l}\text { Corticosteroides, preparações } \\
\text { dermatológicas }\end{array}$ & & $1(0,8 \%)$ \\
\hline $\begin{array}{l}\text { Preparações para } \\
\text { tosse e resfriado }\end{array}$ & & $5(3,8 \%)$ \\
\hline Diuréticos & & $1(0,8 \%)$ \\
\hline $\begin{array}{l}\text { Medicamentos para } \\
\text { doenças gástricas }\end{array}$ & & $9(6,8 \%)$ \\
\hline Medicamentos para constipação & & $2(1,5 \%)$ \\
\hline $\begin{array}{l}\text { Medicamentos para transtornos } \\
\text { gastrointestinais funcionais }\end{array}$ & & $6(4,5 \%)$ \\
\hline $\begin{array}{l}\text { Medicamentos para as doenças } \\
\text { das vias aéreas obstrutivas }\end{array}$ & & $1(0,8 \%)$ \\
\hline $\begin{array}{l}\text { Medicamentos para tratamento } \\
\text { das doenças ósseas }\end{array}$ & & $4(3 \%)$ \\
\hline $\begin{array}{l}\text { Medicamentos usados } \\
\text { em diabetes }\end{array}$ & & $4(3 \%)$ \\
\hline Imunoestimulantes & & $2(1,5 \%)$ \\
\hline Antilipêmicos & & $2(1,5 \%)$ \\
\hline Suplementos minerais & & $1(0,8 \%)$ \\
\hline Relaxantes musculares & & $1(0,8 \%)$ \\
\hline Preparações nasais & & $1(0,8 \%)$ \\
\hline $\begin{array}{l}\text { Outros medicamentos do } \\
\text { sistema nervoso no ATC }\end{array}$ & & $2(1,5 \%)$ \\
\hline Psicoanalépticos & & $5(3,8 \%)$ \\
\hline Psicolépticas & & $3(2,3 \%)$ \\
\hline Drogas de terapia tireoide & & $2(1,5 \%)$ \\
\hline Vasoprotetivos & & $2(1,5 \%)$ \\
\hline Desconhecido & \multirow[t]{6}{*}{$6^{\circ}$} & $2(3,8 \%)$ \\
\hline $\begin{array}{l}\text { Agentes que agem no sistema } \\
\text { renina-angiotensina }\end{array}$ & & $2(3,8 \%)$ \\
\hline Analgésicos & & $5(9,4 \%)$ \\
\hline Preparações antianêmicas & & $1(1,9 \%)$ \\
\hline $\begin{array}{l}\text { Antibacterianos para } \\
\text { uso sistêmico }\end{array}$ & & $2(3,8 \%)$ \\
\hline $\begin{array}{l}\text { Antidiarreicos, agentes } \\
\text { anti-inflamatórios/ } \\
\text { anti-infecciosos intestinais }\end{array}$ & & $1(1,9 \%)$ \\
\hline
\end{tabular}

\begin{tabular}{|c|c|c|}
\hline Antieméticos & \multirow[t]{24}{*}{$6^{\circ}$} & $2(3,8 \%)$ \\
\hline Anticonvulsivantes & & $2(3,8 \%)$ \\
\hline $\begin{array}{l}\text { Anti-histamínicos para } \\
\text { uso sistêmico }\end{array}$ & & $1(1,9 \%)$ \\
\hline Antimicóticos para uso sistêmico & & $1(1,9 \%)$ \\
\hline Agentes antitrombóticos & & $3(5,7 \%)$ \\
\hline $\begin{array}{l}\text { Agentes bloqueadores } \\
\text { beta-adrenérgicos }\end{array}$ & & $1(1,9 \%)$ \\
\hline Drogas de terapia cardíaca & & $2(3,8 \%)$ \\
\hline $\begin{array}{l}\text { Corticosteroides para } \\
\text { uso sistêmico }\end{array}$ & & $2(3,8 \%)$ \\
\hline $\begin{array}{l}\text { Preparações para } \\
\text { tosse e resfriado }\end{array}$ & & $1(1,9 \%)$ \\
\hline Diuréticos & & $2(3,8 \%)$ \\
\hline $\begin{array}{l}\text { Medicamentos para } \\
\text { doenças gástricas }\end{array}$ & & $2(3,8 \%)$ \\
\hline Medicamentos para constipação & & $1(1,9 \%)$ \\
\hline $\begin{array}{l}\text { Medicamentos para transtornos } \\
\text { gastrointestinais funcionais }\end{array}$ & & $1(1,9 \%)$ \\
\hline $\begin{array}{l}\text { Medicamentos para as doenças } \\
\text { das vias aéreas obstrutivas }\end{array}$ & & $1(1,9 \%)$ \\
\hline $\begin{array}{l}\text { Medicamentos para tratamento } \\
\text { das doenças ósseas }\end{array}$ & & $4(7,5 \%)$ \\
\hline $\begin{array}{l}\text { Medicamentos usados } \\
\text { em diabetes }\end{array}$ & & $2(3,8 \%)$ \\
\hline Antilipêmicos & & $2(3,8 \%)$ \\
\hline Suplementos minerais & & $1(1,9 \%)$ \\
\hline $\begin{array}{l}\text { Outros medicamentos do } \\
\text { sistema nervoso no ATC }\end{array}$ & & $1(1,9 \%)$ \\
\hline Psicoanalépticos & & $2(3,8 \%)$ \\
\hline Psicolépticas & & $1(1,9 \%)$ \\
\hline Drogas de terapia tireoide & & $2(3,8 \%)$ \\
\hline Urológicos & & $1(1,9 \%)$ \\
\hline Vasoprotetivos & & $2(3,8 \%)$ \\
\hline Desconhecido & 70 & $1(6,3 \%)$ \\
\hline Analgésicos & & $1(6,3 \%)$ \\
\hline Preparações antianêmicas & & $1(6,3 \%)$ \\
\hline $\begin{array}{l}\text { Antibacterianos para } \\
\text { uso sistêmico }\end{array}$ & & $2(12,5 \%)$ \\
\hline $\begin{array}{l}\text { Antidiarreicos, agentes } \\
\text { anti-inflamatórios/ } \\
\text { anti-infecciosos intestinais }\end{array}$ & & $1(6,3 \%)$ \\
\hline Antieméticos & & $2(12,5 \%)$ \\
\hline Anticonvulsivantes & & $1(6,3 \%)$ \\
\hline $\begin{array}{l}\text { Anti-histamínicos para } \\
\text { uso sistêmico }\end{array}$ & & $1(6,3 \%)$ \\
\hline Agentes antitrombóticos & & $1(6,3 \%)$ \\
\hline $\begin{array}{l}\text { Corticosteroides para } \\
\text { uso sistêmico }\end{array}$ & & $1(6,3 \%)$ \\
\hline
\end{tabular}




\begin{tabular}{|c|c|c|}
\hline Diuréticos & \multirow[t]{4}{*}{70} & $1(6,3 \%)$ \\
\hline $\begin{array}{l}\text { Medicamentos para } \\
\text { doenças gástricas }\end{array}$ & & $1(6,3 \%)$ \\
\hline $\begin{array}{l}\text { Medicamentos para tratamento } \\
\text { das doenças ósseas }\end{array}$ & & $1(6,3 \%)$ \\
\hline Antilipêmicos & & $1(6,3 \%)$ \\
\hline $\begin{array}{l}\text { Antibacterianos para } \\
\text { uso sistêmico }\end{array}$ & \multirow[t]{5}{*}{$8^{\circ}$} & $1(16,7 \%)$ \\
\hline $\begin{array}{l}\text { Antidiarreicos, agentes } \\
\text { anti-inflamatórios/ } \\
\text { anti-infecciosos intestinais }\end{array}$ & & $2(33,3 \%)$ \\
\hline Antivirais para uso sistêmico & & $1(16,7 \%)$ \\
\hline $\begin{array}{l}\text { Agentes bloqueadores } \\
\text { beta-adrenérgicos }\end{array}$ & & $1(16,7 \%)$ \\
\hline Psicolépticas & & $1(16,7 \%)$ \\
\hline $\begin{array}{l}\text { Anti-histamínicos para } \\
\text { uso sistêmico }\end{array}$ & 90 & $1(100 \%)$ \\
\hline Analgésicos & \multirow{2}{*}{$\begin{array}{c}\text { Melhor } \\
\text { atendimento } \\
\text { de suporte }\end{array}$} & $5(21,7 \%)$ \\
\hline $\begin{array}{l}\text { Antibacterianos para } \\
\text { uso sistêmico }\end{array}$ & & $4(17,4 \%)$ \\
\hline
\end{tabular}

\begin{tabular}{|c|c|c|}
\hline $\begin{array}{l}\text { Antidiarreicos, agentes } \\
\text { anti-inflamatórios/ } \\
\text { anti-infecciosos intestinais }\end{array}$ & \multirow[t]{11}{*}{$\begin{array}{l}\text { Melhor } \\
\text { atendimento } \\
\text { de suporte }\end{array}$} & $2(8,7 \%)$ \\
\hline Antieméticos & & $1(4,3 \%)$ \\
\hline $\begin{array}{l}\text { Anti-histamínicos para } \\
\text { uso sistêmico }\end{array}$ & & $1(4,3 \%)$ \\
\hline $\begin{array}{l}\text { Produtos anti-inflamatórios } \\
\text { e antirreumáticos }\end{array}$ & & $1(4,3 \%)$ \\
\hline $\begin{array}{l}\text { Corticosteroides para } \\
\text { uso sistêmico }\end{array}$ & & $2(8,7 \%)$ \\
\hline $\begin{array}{l}\text { Medicamentos para } \\
\text { doenças gástricas }\end{array}$ & & $1(4,3 \%)$ \\
\hline Medicamentos para constipação & & $2(8,7 \%)$ \\
\hline $\begin{array}{l}\text { Medicamentos para transtornos } \\
\text { gastrointestinais funcionais }\end{array}$ & & $1(4,3 \%)$ \\
\hline $\begin{array}{l}\text { Medicamentos para as doenças } \\
\text { das vias aéreas obstrutivas }\end{array}$ & & $1(4,3 \%)$ \\
\hline $\begin{array}{l}\text { Medicamentos para tratamento } \\
\text { das doenças ósseas }\end{array}$ & & $1(4,3 \%)$ \\
\hline Psicolépticas & & $1(4,3 \%)$ \\
\hline
\end{tabular}

Anexo 3. Custos totais divididos por tipo de recurso e linha de tratamento em $\mathrm{R} \$$

\begin{tabular}{|c|c|c|c|c|c|c|c|c|}
\hline \multirow[t]{2}{*}{ Recurso } & \multicolumn{8}{|c|}{ Linha de tratamento } \\
\hline & $1 L(n=152) R \$$ & $2 L(n=152) R \$$ & $3 L(n=86) R \$$ & $4 L(n=48) R \$$ & $5 L(n=27) R \$$ & $6 L(n=12) R \$$ & $7 L(n=5) R \$$ & $8 L(n=1) R \$$ \\
\hline Quimioterapia & $3.467 .695,70$ & $2.540 .064,80$ & $1.363 .305,10$ & $687.207,50$ & $509.858,90$ & $321.379,00$ & $37.786,90$ & $3.449,40$ \\
\hline Terapia de manutenção* & $1.955 .400,30$ & $325.893,10$ & $124.592,20$ & $43.605,60$ & $47.328,70$ & - & - & - \\
\hline Radioterapia & $277.995,40$ & $261.644,00$ & $313.056,20$ & $16.378,30$ & $41.686,80$ & $4.031,40$ & $5.444,60$ & - \\
\hline Cirurgia & $9.705,30$ & $4.650,40$ & $1.706,60$ & 452,80 & 589,30 & - & - & - \\
\hline Exames & $242.344,90$ & $183.419,30$ & $111.318,30$ & $63.012,90$ & $30.025,20$ & $17.704,70$ & $2.051,60$ & 29,30 \\
\hline Cuidado ambulatorial & $24.391,30$ & $17.895,40$ & $10.929,20$ & $7.229,20$ & $3.719,00$ & $1.166,70$ & 441,60 & 1,80 \\
\hline Internação & $33.659,50$ & $100.914,80$ & $91.586,40$ & $31.003,70$ & $11.690,50$ & $6.429,90$ & - & - \\
\hline Emergências & 291,40 & 654,10 & 136,90 & 474,60 & - & 18,70 & 21,30 & - \\
\hline Procedimentos de suporte & $3.435,90$ & $3.109,70$ & $3.722,00$ & $1.110,80$ & 873,60 & 582,50 & - & - \\
\hline Total & $6.014 .919,60$ & $3.438 .245,50$ & $2.020 .352,90$ & $850.475,40$ & $645.771,90$ & $351.313,00$ & $45.746,20$ & $3.480,50$ \\
\hline
\end{tabular}

* Terapia de manutenção foi definida pelo protocolo como "a continuação de um ou mais agentes a partir da manutenção da linha após 4 a 6 ciclos de terapia". 